\title{
Summary Report for the Virtual Summit on Decarbonizing the Agriculture Sector
}

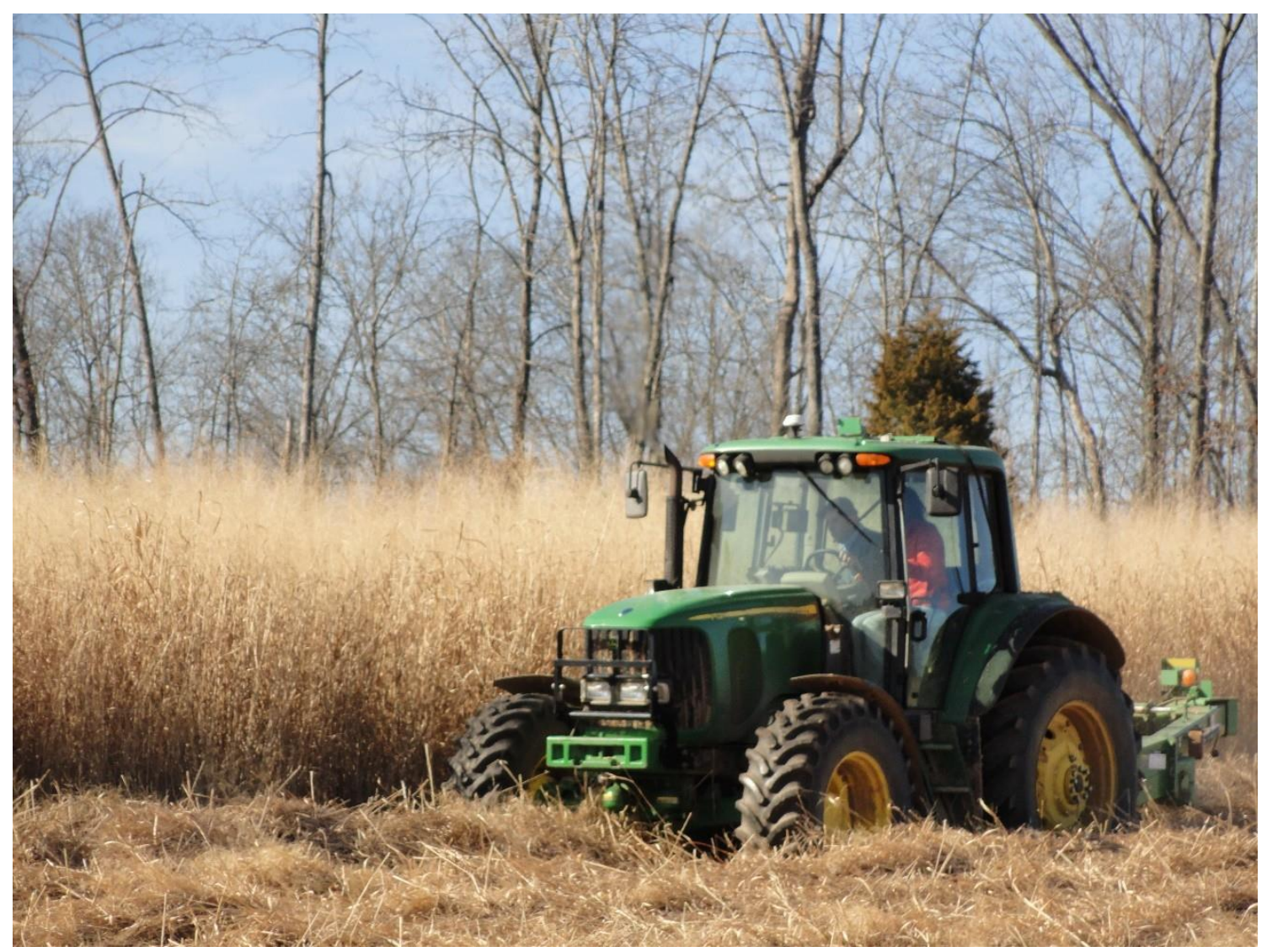

Brian H. Davison

Robert M. Wagner

Gerald A. Tuskan

November 2021 


\title{
DOCUMENT AVAILABILITY
}

Reports produced after January 1,1996, are generally available free via OSTI.GOV.

Website www.osti.gov

Reports produced before January 1, 1996, may be purchased by members of the public from the following source:

\author{
National Technical Information Service \\ 5285 Port Royal Road \\ Springfield, VA 22161 \\ Telephone 703-605-6000 (1-800-553-6847) \\ TDD 703-487-4639 \\ Fax 703-605-6900 \\ E-mailinfo@ntis.gov \\ Website http://classic.ntis.gov/
}

Reports are available to US Department of Energy (DOE) employees, DOE contractors, Energy Technology Data Exchange representatives, and International Nuclear Information System representatives from the following source:

Office of Scientific and Technical Information

PO Box 62

Oak Ridge, TN 37831

Telephone 865-576-8401

Fax 865-576-5728

E-mail reports@osti.gov

Website https://www.osti.gov/

\begin{abstract}
This report was prepared as an account of work sponsored by an agency of the United States Government. Neither the United States Government nor any agency thereof, nor any of their employees, makes any warranty, express or implied, or assumes any legal liability or responsibility for the accuracy, completeness, or usefulness of any information, apparatus, product, or process disclosed, or represents that its use would not infringe privately owned rights. Reference herein to any specific commercial product, process, or service by trade name, trademark, manufacturer, or otherwise, does not necessarily constitute or imply its endorsement, recommendation, or favoring by the United States Government or any agency thereof. The views and opinions of authors expressed herein do not necessarily state or reflect those of the United States Government or any agency thereof.
\end{abstract}

Cover image: Switchgrass harvest in Vonore, Tennessee. Photo courtesy of Erin G. Webb. 


\title{
SUMMARY REPORT FOR THE VIRTUAL SUMMIT ON DECARBONIZING THE
} AGRICULTURE SECTOR, SEPTEMBER 21-22, 2021, HOSTED BY ORNL

\author{
Brian H. Davison \\ Robert M. Wagner \\ Gerald A. Tuskan
}

November 2021

Prepared by

OAK RIDGE NATIONAL LABORATORY

Oak Ridge, TN 37831

managed by

UT-BATTELLE LLC

for the

US DEPARTMENT OF ENERGY

under contract DE-AC05-00OR22725 



\section{CONTENTS}

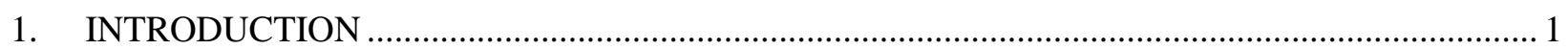

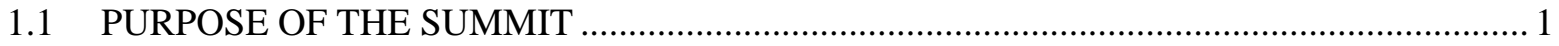

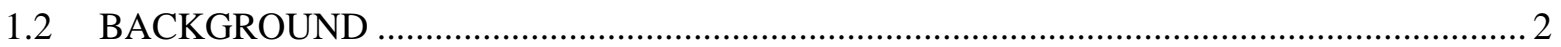

1.3 SOCIAL MEDIA— \#AGDECARB …….................................................................. 2

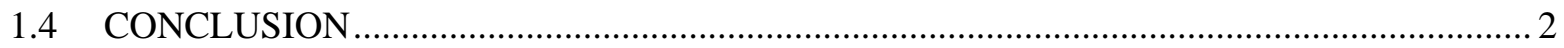

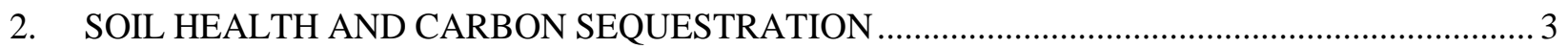

2.1 TOPIC 1A: SOIL CARBON DYNAMICS AND MANIPULATION …................................ 3

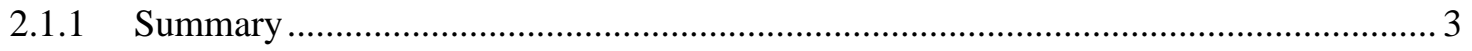

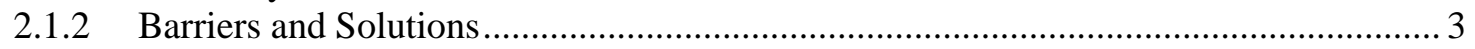

2.2 TOPIC 1B: IMPROVING NITROGEN USE EFFICIENCY AND SOIL NITROGEN

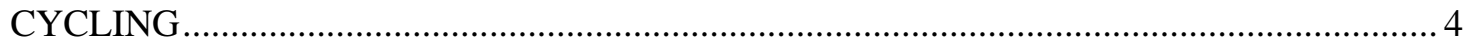

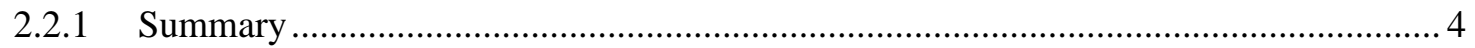

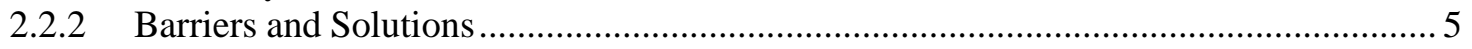

2.3 TOPIC 1C: SOIL MEASUREMENT, MONITORING AND VERIFICATION ..................... 6

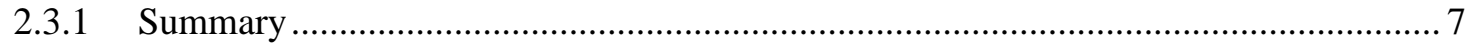

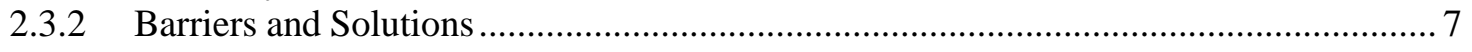

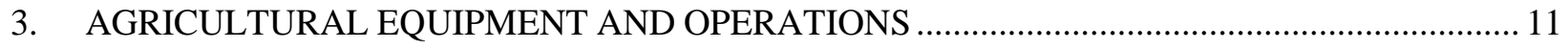

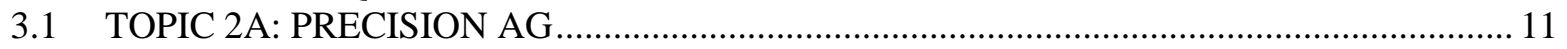

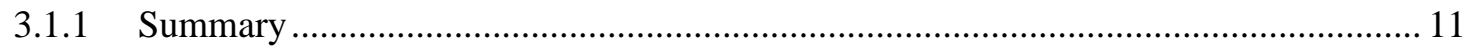

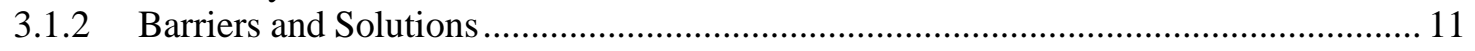

3.2 TOPIC 2B: AGRICULTURE EQUIPMENT POWER AND PROPULSION …................... 14

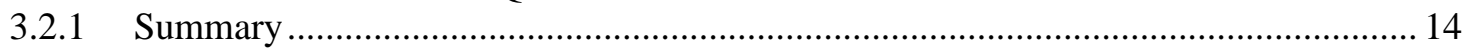

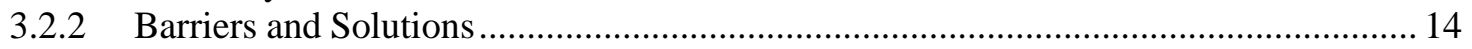

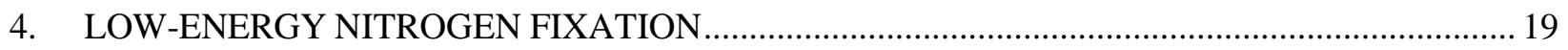

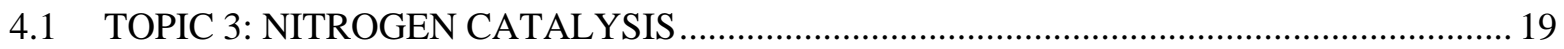

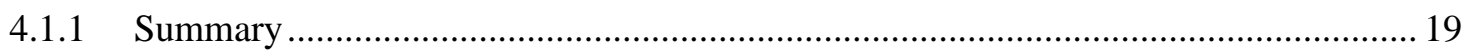

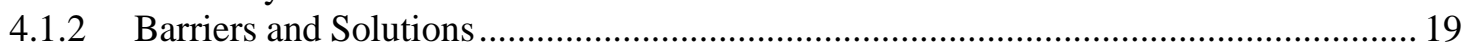

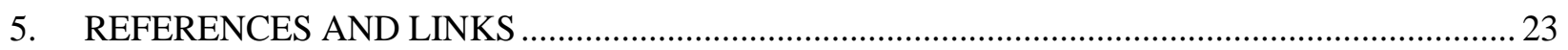

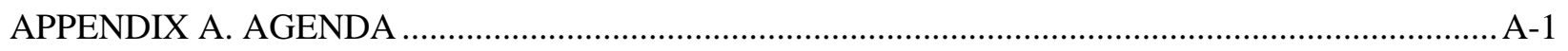

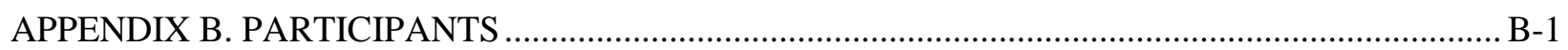

APPENDIX C. DRAFT WHITE PAPER FROM ORNL-JULY 2021 ........................................... C-1

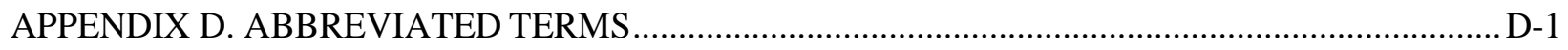





\section{INTRODUCTION}

A virtual summit on decarbonizing the agriculture sector was organized on September 21-22, 2021, by Oak Ridge National Laboratory (ORNL) in anticipation of federal activities surrounding a greater role for the US Department of Energy (DOE) in support of the US Department of Agriculture (USDA) in areas related to climate and carbon impacts on the US agriculture sector. A series of thought-provoking talks were presented by leaders from industry, academia, and DOE (see attachment - final agenda, Appendix A). About 50 to 70 scientists and engineers actively participated at any one time during the summit in the talks and in the topical breakouts (Appendix B).

\subsection{PURPOSE OF THE SUMMIT}

Development and deployment of decarbonization measures in the agriculture sector have potential benefits beyond enhanced carbon drawdown and sequestration in soil, to reduce energy consumption while expanding the agro-industrial bioeconomy. Building on the current state of the science and on expertise, ORNL identified three areas where we believe DOE can have a significant impact: soil health and carbon sequestration, agricultural vehicles and operations, and low-energy nitrogen input and releases. They include opportunities to reduce emissions from inputs, energy use, and soils and to increase carbon sinks and system productivity. If the United States is to reach its 2050 emissions goals, it will need to consider the significant decarbonization potential in the agriculture sector, and it will need to use multidisciplinary scientific expertise and frontier technologies and engage academia, industry, and federal agencies in assessing, improving and deploying decarbonization technologies. We will also need methods to value and validate agricultural decarbonization approaches which will be a widely distributed efforts with multiple stakeholders.

Our goals were to identify and rank key barriers in these three topics, to list possible solutions and crosscuts for the top five barriers in each subtopic, and to generate an initial list of experts and points of contacts for potential collaborations in response to anticipated new funding opportunities from various DOE program offices. Participants prepared an "Introduction Bio Slide."

The three topics were described in more detail in a draft white paper developed by ORNL in July 2021 (Appendix C) and shared with the participants. We did not emphasize animal husbandry, food processing, or food waste, which, while very important, are more central to USDA's expertise.

There were six topical breakouts for identification of barriers.

- Soil health and carbon sequestration

- 1a: Soil carbon dynamics and manipulation; Chris Schadt, Moderator, Jessica Moore, Scribe

- 1b: Improving nitrogen use efficiency; Melissa Cregger moderator, Matt Craig, Scribe

$\circ$ 1c: Soil measurement, monitoring, and verification; John Field, moderator, Maggie Davis, Scribe

- Agricultural equipment and operations

○ 2a: Precision ag; Erin Webb Moderator, Esther Parish Scribe

○ 2b: Equipment power and propulsion; Josh Pihl, Moderator, Jim Szybist, Scribe

- Low-energy nitrogen fixation

○ 3: Nitrogen catalysis; Gabriel Veith, Moderator, Robert Sacci, Scribe

○ Note: Bionitrogen fixation was included under the topic $1 b$. 


\subsection{BACKGROUND}

Why should the United States consider "Decarbonizing the Agriculture Sector"? It has more than 900 million acres of agricultural quality land, approximately 420 million acres of which is in commercial production. Food production accounts for as much as one-third of total global greenhouse gas emissions. Implementing changes in the agriculture sector will contribute to enhanced natural processes and to an expansion of the emerging bioeconomy. The recent DOE budget request and authorizations calls out DOE to support USDA in this area.

\subsection{SOCIAL MEDIA—\#AGDECARB}

Several quotes from workshop presenters were shared on social media using the hashtag \#AgDecarb. The same hashtag is being used to continue the conversation. There was also an ORNL press release on September 21, 2021 - https://www.ornl.gov/news/agricultural-decarbonization-gets-new-emphasis-ornl.

\subsection{CONCLUSION}

Collectively, we identified more than 30 key barriers and proposed possible solutions. Each barrier or solution can be a starting point for further proposal and team development. This report outlines the potential for major impacts using national laboratory and DOE strengths applied to the agriculture sector. This report should be considered a working document. Our goal is to be better prepared to assemble teams in anticipation of DOE funding opportunity announcements from the Office of Energy Efficiency and Renewable Energy (EERE), the Office of Biological and Environmental Research (BER), the Office of Fossil Energy and Carbon Management (FECM), the proposed Advanced Research Projects AgencyClimate (ARPA-C), and the Advanced Research Projects Agency-Energy (ARPA-E), among others.

The summit allowed the participants to begin to develop working relationships; however, more effort is needed in this area to build effective teams and to develop relationships. We view the summit is as a start of cross-domain ideation on decarbonization strategies for the agriculture sector, not a conclusion or a limitation on ideas and team members. 


\section{SOIL HEALTH AND CARBON SEQUESTRATION}

\subsection{TOPIC 1A: SOIL CARBON DYNAMICS AND MANIPULATION}

Moderator: Chris Schadt

Scribe: Jessica Moore

\subsubsection{Summary}

Soils are critical components of Earth's biogeochemical cycles. While it is known that soils are structurally, chemically, and biologically heterogenous and complex, we lack an understanding of the spatiotemporal heterogeneity and how soil-forming factors, land use history, and geomorphology may drive variation in soil organic carbon (SOC) dynamics and the formation and structural complexities of, for example, microaggregates and macroaggregates. Our conceptualizations currently remain simplistic with respect to critical biogeochemical interfaces such as the rhizosphere and vadose zone across depth gradients from the surface to subsurface soils. A primary barrier contributing to the dearth of sampling is infrastructure to support high-throughput repeated soil sampling. Such infrastructure may currently exist in a few locations, yet a replicated network of experimental sites that support nondestructive, repeated, high- throughput, belowground sampling across a range of soil types is still lacking. Plant systems are yet another critical component of $\mathrm{C}$ biogeochemical cycles. There are knowledge gaps in our understanding of how aboveground and belowground plant traits influence soil properties and vice versa. Inconsistencies also remain in soil organic matter (SOM) conceptualization and measurement standards. For example, to understand how deeply rooted plants of a certain chemotype contribute to SOC accumulation longer residence time of $\mathrm{C}$, we need experiments that track and manipulate plant inputs and their transformations in soil and the timing of precipitation and to quantify how precipitation timing is related to SOC accumulation and microbial respiration. Coupled probing of chemistry, biology, and physical mechanisms in lab-to-field experiments can lead an understanding of SOC storage as a factor of soil type. This breakout session identified the following top barriers:

- Lack of consensus on a conceptualization framework for SOC/SOM dynamics

- Lack of (a) research infrastructure and (b) robust sampling schemes for collecting data in the heterogenous soil environment

- Knowledge gaps in managing or improving above-belowground plant performance and plant-soil interactions that promote SOC accumulation without reducing nutrient mineralization

- Knowledge gaps in effects of soil- forming factors

\subsubsection{Barriers and Solutions}

- Lack of consensus on a conceptualization framework for SOC dynamics

- Standardize methods across labs for SOC measurement

- Develop methods and models that build upon a standard mineral-associated organic matter/particulate organic matter [MAOM/POM]) two-pool structure by adding layered complexity upon base measurements

- Account for aggregates with consideration of above

- Crosscut topics:

- A clearinghouse (i.e., an agreed-upon suite of models) is needed so that we can interface with AI and industry partners to develop decision support tools. 
- Lack of (a) research infrastructure and (b) robust sampling schemes for collecting data in the heterogenous soil environment

$\circ$ Networks of smart farms and controlled environment facilities with focus on belowground processes and access

- Dedicated plots and field experiments that allow belowground sampling focus at the needed level of resolution (e.g., replication of genome-wide association studies (GWAS) and quantitative trait locus (QTL) trials so that destructive belowground sampling can be done without interfering with aboveground trait variation studies)

- More high-throughput sampling approaches with consideration for temporal scales of these processes

- Improved technology for nondestructive or less destructive sampling with lower sample mass/volume

- Better designs for study and verification strategies to capture and account for high spatial and temporal variability

- Crosscut topics:

- Modelers to develop artificial intelligence (AI) and process models supporting a management framework

- Decision support tools (models) for multiple goals of carbon sequestration and crop yield

- Knowledge gaps for managing plant-soil interactions that promote SOC accumulation without reducing nutrient mineralization

- Develop and grow deep-rooted plants to achieve more SOC accumulation at depth

- Conduct studies to better understand the role of short- and long-term precipitation patterns in driving SOC dynamics

$\circ$ Increase the study of plant root chemistry effects on rhizosphere dynamics and resulting SOC chemistry and stability

- Crosscut topics:

- We envision these new experimental data could be used to create a management model that incorporates multiple data streams and analytics into a decision-making tool.

- Knowledge gaps in effects of soil-forming factors

$\circ$ Establish standardized long-term experimental network of sites across diverse soil orders and ecoregions

- Conduct coupled lab-scale experiments that allow manipulation of soil forming factors to understand effects on SOC dynamics

- Crosscut topics:

- Develop cutting- edge technologies that can elucidate SOC (de)stabilization processes

- Leverage existing networks to the USDA Long-Term Agroecosystem Research (LTAR) Network, the NSF Long-Term Ecological Research (LTER) Network, and critical zone observatories where possible

\subsection{TOPIC 1B: IMPROVING NITROGEN USE EFFICIENCY AND SOIL NITROGEN CYCLING}

Moderator: Melissa Cregger

Scribe: Matt Craig

\subsubsection{Summary}

This breakout session was focused to identify the top barriers to increasing soil nitrogen concentrations, increasing plant nitrogen use efficiency, and reducing nitrogen loss from agroecosystems. Given the 
background of the participants, the main focus was on understanding and optimizing soil nitrogen cycling by developing and leveraging biological, physical, and engineering tools. While this group lacked the necessary expertise in plant engineering and physiology, an obvious gap that needs to be addressed is developing and optimizing methods to engineer biological nitrogen fixation directly into plants or stable plant-microbe associations. The following top barriers were identified:

- The environmental controls on nitrogen cycling across ecosystems are unknown.

- Nitrogen asynchrony: There is a temporal disconnect among $\mathrm{N}$ cycling processes.

- Belowground interactions are complex and often difficult to predict.

- Nitrogen concentrations and fluxes are inadequately mapped across the globe.

- Measuring nitrogen- cycling processes is difficult.

\subsubsection{Barriers and Solutions}

- The environmental controls on nitrogen cycling across ecosystems are unknown.

- Leverage ongoing research in natural ecosystems to inform processes in agro/bioenergy systems

- Develop and improve models that incorporate the whole nitrogen cycle and can be used to inform research priorities

- Quantify the variation of controls on nitrogen cycling among different crop ecosystems

- Crosscut topics:

- Mechanistic understanding to inform modeling effort

- Assessment of top and subsurface soil N pool data for models

- Improved multi-omic data synthesis related to steps in the $\mathrm{N}$ cycle

○ Possible teaming:

- European N summit

- Powell Center N consortium-Verity Salmon(ORNL)

- Nitrogen asynchrony: There is a temporal disconnect between $\mathrm{N}$ cycling processes.

- Characterize temporal fluctuation of soil $\mathrm{N}$ using continuous $\mathrm{N}$ measurements (gas fluxes, runoff, plant status) over seasons

- Measure rapid losses of soil $\mathrm{N}$ using physics, hydrology, and bioengineering solutions

$\circ$ (e.g., manipulating plant traits or microbial communities to alleviate the temporal mismatch of certain processes)

- Leverage already available data on $\mathrm{N}$ flux by monitoring groundwater and well water

- Characterize surface and subsurface litter, which may be important for seasonal timing of $\mathrm{N}$ immobilization

- Incorporate the "indirect" $\mathrm{N}$ loss in ecosystem models

- Crosscut topics:

- High- resolution geophysical techniques to assess nitrogen cycling

- Models to improve prediction of $\mathrm{N}$ asynchronous fluxes

- Effective communication and connections with farmers to assess $\mathrm{N}$ disconnect

○ Possible teaming:

- European N summit

- Belowground interactions are complex and often difficult to predict.

- Develop integrated across kingdom research using standardized methods and systems

- Develop integrated process-based modeling and measurement research (e.g., the Model

Observation/Experiment [MODEX] process)

- Integrate metagenome information into ecosystem models

- Use multi-omic techniques to translate gene- level data to ecosystem processes 
- Use geoscience approaches to integrate subsurface and surface dynamics

- Crosscut topics:

- Microbially explicit models (e.g., the Carbon, Organisms, Rhizosphere, and Protection in the Soil Environment [CORPSE] model)

- Similar models provide good opportunity for improving aboveground/belowground interactions and $\mathrm{C}-\mathrm{N}$ interactions; these models could be improved with other relevant chemical factors.

- Improve database of N-fixer genomes and Nif/Anf genes

- Lisa Tiemann, Michigan State University (MSU) is working on such a database.

○ Possible teaming:

- Trent Northen, Lawrence Berkeley National Laboratory (LBNL) is using EcoFabs to standardize experiments.

- Kirsten Hofmockel, Pacific Northwest National Laboratory (PNNL) leads the BER Soil Microbiome SFA, https://genomicscience.energy.gov/research/sfas/pnnl.shtml.

- Nitrogen concentration and flux is inadequately mapped across the globe.

- Initiate training programs and funding opportunities for underrepresented research areas

- Develop international partnerships

- Construct multiple model comparisons for global croplands related to $\mathrm{N}$ cycles and $\mathrm{N}_{2} \mathrm{O}$ emissions

- Engineer nanoparticle to easily assess $\mathrm{N}$ flux

- Map surface and subsurface nitrogen

- Leverage existing data streams through municipal water facilities to map $\mathrm{N}$ flux

- Crosscut needs

- SURFACE Topology Model

- Model-data fusion/AI approaches

- Possible teaming

- Hanqin Tian (Auburn: coordinator of NMIP-2: global Nitrogen/ $\mathrm{N}_{2} \mathrm{O}$ Model Intercomparison Project)

- Nutrient Network

- International nitrogen initiative

- Measuring nitrogen cycling processes is difficult.

$\circ$ Establish a network of field $\mathrm{N}$ fixation and $\mathrm{N}_{2} \mathrm{O}$ emission measurements

$\circ$ Engineer solutions (e.g., develop and/or use biosensors, smart tracers, or monitoring chips to assess fluxes of nitrogen species in soils)

- Optimize proteomic stable isotope probing (SIP); develop better methods to work in different soil types

- Crosscut topics:

- DOE-SBIR/STTR for biosensor development

- Machine learning or mechanistic modeling to scale measurements across space and time

- Possible teaming:

- Carrie Masiello (biosensors)

- Mary Lipton/ Jim Moran PNNL (SIP-Proteomics)

- Rich Giannone ORNL

- Industry partners (QIO, QuantumPro)

\subsection{TOPIC 1C: SOIL MEASUREMENT, MONITORING AND VERIFICATION}

Moderator: John Field

Scribe: Maggie Davis 


\subsubsection{Summary}

The charge of this breakout session was to examine barriers to measuring, monitoring, and verifying soil carbon (C) levels and related soil greenhouse gases (GHGs) to provide a more rigorous basis for policymaking or valuation. In the opening plenary session, speaker A. J. Kumar highlighted the efforts of Indigo Ag in this area, including the need for protocols to standardize modeling and accounting efforts. Breakout participants then broadly examined these issues in the context of both conventional annual cropping systems and under future biomass feedstock crops. The group collaboratively identified and ranked the following five critical barriers to improved soil measurement, monitoring, and verification that should be addressed in future research efforts as follows (rated from most to least important):

- High cost of thorough field sampling

- Lack of data-model integration tools

- Limited separation of measurable SOC pools

- Interpretation and accounting standards

- Lack of historic and current land management data

These barriers address interrelated issues around the adequacy of existing soil measurement methods, the need for increased data collection and access, and the integration of these observations with process-based ecosystem models. We discussed the pressing need to develop both cheaper soil $\mathrm{C}$ measurement techniques, and models and other technology to minimize monitoring costs across heterogeneous landscapes. There was also a brief discussion of existing soil core databases and whether soil $\mathrm{C}$ modeling remains a "data-poor" enterprise. We identified data as a crosscutting barrier, with a pressing need for centralized repositories that follow Findable, Accessible, Interoperable, and Reusable (FAIR) guidelines and best data management practices (e.g., robust metadata).

\subsubsection{Barriers and Solutions}

- High cost of thorough field sampling-Field sampling (e.g., soil core collection) and laboratory analysis required to accurately measure heterogeneity in soil $\mathrm{C}$ across space and depth are costly and time-consuming.

- Develop new in situ measurement methods, possibly based on optical or combustion techniques, and deployed on agricultural equipment (e.g., plows) or miniaturized into low-cost sensors broadcast into the soil.

- Refine spectral sensing methods, which researchers can deploy either in situ or remotely.

- Adopt more standardized stratification approaches and soil core sampling methods for deployment in different sites across different ecosystem types. Methods are simplified where appropriate.

○ Crosscut: tbd

- Possible teaming:

- John Deere

- Colorado State University (CSU) Soil Solutions Center

- Marcelo Galdos (University of Leeds)

- Indigo Ag (A. J. Kumar)

- Veris Technologies (plow-mounted in situ spectral measurement)

- Drone developers

- Lack of data-model integration tools-We lack standardized soil C measurement databases linked to transparent, easy-to-use models, which are necessary for rigorous uncertainty quantification in monitoring and verification. 
- Compile existing soil measurements into readily accessible public databases that adhere to FAIR guidelines and best management practices for long-term archival of datasets and bolster the use of existing datasets such as SoilHealthDB or the World Soil Information Service Soil Profile

Database.

- Create long-term soil-sampling programs that contribute to associated public databases (similar to LUCAS).

- Develop interoperable, model-agnostic data assimilation platforms that use new observationaldata to update model state, enabling iterative, near-term forecasting.

- Use artificial intelligence to create surrogate models with reduced computational complexity, which can dramatically reduce model run time and make possible new sensitivity analysis, uncertainty quantification, and data assimilation approaches.

○ Possible teaming:

- Jianwei Ziqi and Kaiyu Guan (the University of Illinois at Urbana-Champaign [UIUC])

- A.J. Kumar (Indigo Ag)

- Ben Brown (LBNL)

- Dan Ricciuto (ORNL)

- Dan Jacobson (ORNL)

- Earth System Informatics and Data Discovery Section (ORNL)

- Limited separation of measurable soil C pools - Basic fractionation to separate POM from MAOM is not yet universally applied to soil core samples or used to inform soil carbon permanence estimates or management goals.

- Develop higher-throughput or more automated soil fractionation methods, and related measurements of nitrogen and phosphorous.

○ Develop in situ methods for soil fractionation or sensing of related proxies for different soil C pools.

- Mature process-based models built around measurable soil fractions, with better quantification of the stability and turnover of those fractions.

○ Possible teaming:

- Francesca Cotrufo (CSU)

- Sindhu Jagadamma (UT Institute of Agriculture)

- Melanie Mayes (ORNL)

- Elizabeth Herndon (ORNL)

- Interpretation and accounting standards - Soil carbon crediting is hindered by concerns over additionality (e.g., whether outcomes are novel or would have occurred anyway) and permanence, and uncertainty around the most appropriate baseline or counterfactual against which carbon-building management practices should be evaluated.

- Collaborative development of an international standard (e.g., the International Organization for Standardization [ISO] or ASTM International [formerly known as the American Society for

$\circ$ Testing and Materials]) with input from nongovernmental organizations (NGOs), industry, and government agencies, which would provide common data-based criteria for evaluating different management practices and maximize stakeholder confidence in outcomes.

- Intercomparison studies that review existing soil carbon protocols, elucidate their differences and identify best practices for standards.

- Incorporation of site-level estimates of storage capacity (e.g., MAOM saturation) and timescales of $\mathrm{C}$ storage in different soil fractions.

○ Possible teaming:

- John Deere

- A. J. Kumar (Indigo Ag)

- Other soil C credit companies and certification groups 
- Ziqi Qin (UIUC)

- Keith Kline (ORNL)

- ASTM International

$-\quad$ ISO

- NGOs

- Lack of land management data —-Detailed information on land management (e.g., tillage, fertilizer application, cover cropping) necessary to drive model simulations of current practices and counterfactual scenarios are often considered proprietary and therefore not included in readily accessible public databases.

$\circ$ Develop methods to aggregate and anonymize proprietary data from industry and government programs (e.g., National Resource Inventory, or federal crop insurance programs) into standardized, open-source formats for use in modeling and standards.

$\circ \quad$ Further develop high-resolution land management datasets using remote sensing (e.g., OpTIStillage and cover database).

- Develop standardized, spatially explicit land management histories, including associated uncertainty ranges, to support process-based model intercomparison and Monte Carlo uncertainty quantification.

○ Possible teaming:

- John Deere

- Kaiyu Guan (UIUC)

- A. J. Kumar (Indigo Ag)

- David Lobell (Stanford, has worked with restricted federal crop insurance data)

- Steven Ogle (CSU, has worked with restricted Noble Research Institute [NRI] data)

- Hoyoung Kwon (Argonne National Laboratory [ANL], fertilizer data) 



\section{AGRICULTURAL EQUIPMENT AND OPERATIONS}

\subsection{TOPIC 2A: PRECISION AG}

Moderator: Erin Webb

Scribe: Esther Parish

\subsubsection{Summary}

This group discussed barriers to "digital agriculture" including the need to create space for farmers to pay for and acquire new technologies, preserve and access their data, and capture the opportunities for subsurface carbon sequestration. Agricultural systems are so complex that practical models with appropriate mathematics do not yet exist to deal with so many dimensions. Better sensors and consistent and affordable sampling protocols are needed to truly understand the relationships between individual plants, soil conditions, and land management practices. There is a strong need for trustworthy carbon data, and some worry that the carbon market noise is drowning out real soil health challenges (e.g., soil compaction) and opportunities for other ecosystem services (e.g., water quality improvements). Current carbon markets, developed for forestry systems, do not work well for shorter-term agricultural cycles and changes in land ownership; it will need to be redesigned for successful application to agriculture (e.g., through "carbon-year" payments). Opportunities exist to pay farmers for co-benefits in addition to carbon sequestration, such as improved water quality and increased biodiversity. The following top barriers were identified:

- Lack of consistent, reliable, and affordable soil health and soil carbon data

- Insufficient knowledge of subsurface processes needed to inform management decisions

- High cost of technology and carbon market enrollment (too high for individual farmers)

- Lack of storage and access to original and historical datasets from individual farms prevents understanding of complete mass balance of carbon

- Complexity of agricultural systems makes it hard to predict plant and soil needs

- Lack of sensors that can measure individual plant and soil conditions

\subsubsection{Barriers and Solutions}

- Lack of consistent, reliable, and affordable soil health and soil carbon data.Solutions:

- Develop consensus around a meaningful and affordable measurement of "soil health"

- Develop strategies to fund an accurate and cheap test of carbon sequestration that applies theoryto simple field sampling protocol (e.g., specific measurement depth requirements).

- Develop a continental-scale dataset of soil carbon measurements that has been field-tested. These measurements will need to be tracked over time and at high resolutions.

- Develop accurate and validated models of year-to-year carbon fluxes based on agricultural land management practices.

- Establish public-private partnerships for gathering and sharing datasets. These partnerships will need to include protocol registries, verifiers, and project developers.

- Provide education so that new technology is correctly calibrated and sampling protocols are followed consistently. 
- Allow hedge funds and arbitrage to make a business out of invalidating nonsense carbon credits.

- Crosscut needs: Data repositories and mining, business and resilience models

- Possible Teaming Partners:

- Arva Intelligence:

- $\mathrm{AI} / \mathrm{ML} /$ modeling: Ben Brown,

- CEO: Jay McEntire

- LBNL:

- Precision/digital ag and carbon markets: Michael Schuppenhauer

- Remote sensing and hyperspectral imaging: Nicola Falco

- Reactive transport and reaction diffusion: Carl Steefel

- Data security and privacy: Sean Peisert

- AI/ML for hydrology: Dipankar Dwivedi

- Mesoscale plant/soil models: Esther Singer

- GHG flux analysis: Sebastien Biraud

- Plant-microbe interactions: Romy Chakraborty

- UC Berkeley:

- Microbiome: Jill Banfield

- Insufficient knowledge of subsurface processes needed to inform management decisions

- Establish a forum to coeducate surface and subsurface researchers on the need to work together to develop integrated carbon sequestration models and strategies that include both near- and deepsubsurface carbon flows.

- Develop rich, multimodal datasets with high-resolution belowground imaging and characterizations.

- Develop a concerted effort to collect and store the big datasets need to sample below-ground processes. This will require public-private partnerships.

- Gather more microbiome data and develop a mechanistic understanding of impacts on plants and carbon.

- Translate soil microbe activity data to concrete management decisions.

- Crosscut needs:

- Improve understanding of carbon flows in to the deep subsurface (e.g., through exploiting hydrology)

- Possible teaming partners:

- Arva Intelligence

- $\mathrm{AI} / \mathrm{ML} /$ modeling: Ben Brown,

- CEO: Jay McEntire

- Schlumberger

- Vasudhaven (Sudha) Sudhakar

- LBNL:

- Remote sensing and hyperspectral imaging: Nicola Falco

- Reactive transport and reaction diffusion: Carl Steefel

- Data security and privacy: Sean Peisert

- AI/ML for hydrology: Dipankar Dwivedi

- GHG flux analysis: Sebastien Biraud

- UC Berkeley:

- Deep subsurface microbiome and ecology: Jill Banfield

- High cost of technology and carbon market enrollment (too high for individual farmers)

- Develop new business models for agricultural carbon measurements and credits that work on shorter time scales (e.g., one to several years) rather than trying to use the existing models 
developed for forestry that apply to 40-year cycles. This will lower the risk to market entry and reduce liability as landowners and crops change.

- Pay famers for co-benefits like improved water quality and increased biodiversity (e.g.,ecosystem services in addition to carbon sequestration).

- Enable farmers to get credit for the good practices that they are already doing (e.g., no till).

$\circ$ Invest in the successful cooperative extension programs so that co-op agents can continue toassist farmers in understanding and implementing new technologies and markets.

$\circ$ Develop ways for farmers to access new equipment and technology before the useful life of previous purchases is over.

- Educate multiple stakeholders (e.g., about industry trends, investors, environmental, social and governance (ESG), corporate social responsibility (CSR).

- Improve buffer pools across farmers, communities and carbon programs to drive down risks.

○ Crosscut needs: tbd

- Possible teaming partners: tbd

- Lack of storage and access to original and historical datasets from individual farms prevents understanding of complete mass balance of carbon.

- Include data agreements in land tenure arrangements.

- Preserve original files so that farmers can be eligible for crop insurance.

- Improve data interoperability among commercial platforms (e.g., through development of standards).

- Educate farmers on the need to legibly record "as applied" fertilizer data and other data needed to improve precision ag business management.

- Crosscut Needs: tbd

- Possible Teaming Partners:

- Ag Data Coalition

- Complexity of agricultural systems makes it hard to predict plant and soil needs. Solutions:

- Continue to develop models and AI to predict plant/soil needs.

○ Provide open access, high-throughput quantification methods and models.

- Incorporate socioeconomic dimensions into models such as crop protection, marketing, and behavioral changes.

- Incorporate costs associated with water (including edge-of-field and water treatment) into models in terms of dollars and carbon.

- Optimize ecosystem services, not just crop yields. This will require new math to co-optimize the many variables and dimensions needed for a "smart farm."

$\circ$ Help organizations better understand science-based indicator-targets and outcomes.

○ Crosscut needs: tbd

- Possible teaming partners:

- Standards development organizations

- NGOs

- Investor groups that manage lands

- Reinsurance agencies

- International financial institutions

- Cooperative extension

- Farmers (During the larger group discussion, Brij Singh offered to help connect ORNL to farmers.)

- Lack of sensors that can measure individual plant soil conditions

- Develop better ways to measure physical soil properties such as soil compaction (from heavy machinery). 
○ Develop highly instrumented planters and other vehicles for high-resolution soil maps [e.g., soil electrical conductivity (EC), cation exchange capacity (CEC) and organic matter (OM)]

- Develop drones that have better battery life and fewer flight restrictions.

- Develop carbon and water credits that will cause markets to spur sensor development.

- Crosscut needs:

- Better understanding of the interaction of plant genetics with soil, microbiomes, and climate.

○ Possible teaming partners: tbd

\title{
3.2 TOPIC 2B: AGRICULTURE EQUIPMENT POWER AND PROPULSION
}

\author{
Moderator: Josh Pihl
}

Scribe: Jim Szybist

\subsubsection{Summary}

Farm operations require tractors and other equipment to plant, fertilize, and harvest crops and to perform other operations. This breakout session was focused on identifying barriers and solutions for decarbonized agricultural equipment. The decarbonization pathway included both electrification and utilization of fuels with low or net-zero lifecycle GHG emissions. In particular, the use of ethanol in agricultural equipment was discussed. The topics discussed also included customer acceptance, equipment durability and reliability, cost, and infrastructure (fuel availability or electrical recharging). The top barriers discussed were as follows:

- Availability of low-carbon fuels

- Duty cycle and uptime requirements

- Rural fueling and electrical infrastructure

- Unproven durability of new technologies

- Total cost of ownership and high initial investment

- Lack of lifecycle metrics and regulations

\subsubsection{Barriers and Solutions}

- Availability of low-carbon fuels: Agricultural equipment represents one of the largest investments that farmers make. When the investment is made, farmers need to be sure that the fuel required by the equipment will be readily available, and at a reasonable cost. Thus, there are perceived risks in adopting new technologies.

- Fuel-tolerant engines: Designing engines so that there is flexibility for the end user on the type of fuel that can be used will ensure that farm equipment does not turn into stranded assets. There would likely be limitations to the range of fuel properties a single engine could tolerate, but with variable engine geometry and fuel sensing equipment, engines could be designed to run on a wider range of fuels than they currently do.

- Localized fuel production: Small-scale or localized fuel production at the farm, co-op scale, or as a part of a regional fuel hub would allow farmers to control their own fuel supply. Ideally, fuel production systems would accept multiple feedstocks to ensure availability. Fuel standards would likely need to be modified to enable this type of arrangement.

- Tax incentives: Currently there is a tax discount for off-road petroleum diesel fuel compared to on-road diesel fuel. However, there is no such advantage for using a renewable fuel, such as denatured ethanol (E98). Changing the tax incentives so that they favor renewable fuels rather than petroleum fuels would be an incentive to adopting low-lifecycle carbon fuels, and in doing so, create a demand to make them more available.

- Crosscut topics: 
- Fuel-flexible engines

- Localized fuel production

- Teaming contacts:

- Brij Singh

- Julie Blumreiter

- Jim Szybist

- Duty cycle and uptime requirements: Agricultural equipment operates at high power levels for extended time periods for some farming operations, and current equipment is expected to run continuously during daylight hours with minimal time spent refueling. Long charging times or frequent refueling, which will substantially reduce equipment productivity, will not be accepted by many farmers.

- Fast charging or battery swapping: For electrified powertrains, fast charging or battery swapping would maintain uptime but would also require potentially expensive equipment capabilities and infrastructure upgrades.

- Duty cycle powertrain response: For engines running on decarbonized fuels, there is a need to fully understand the potential engine responses over all temperature and duty cycle requirements with these different fuels. This includes both cold temperature operation and ensuring that the equipment has the same or better performance than the diesel baseline to ensure productivity from the equipment. For electric vehicles, the cooling systems on the batteries, power electronics, and electric machines were identified as an area that required development to ensure that peak torque could be delivered continuously.

- Autonomous operation of farm equipment: By eliminating the need for an operator on every piece of equipment, Autonomous operation-creates opportunities for multiple smaller pieces of farm equipment operating simultaneously, 24/7. Smaller pieces of autonomous equipment, which are more favorable from a safety perspective, could allow for one piece of equipment to charge while another is operating' overnight operation would allow for multiple operation/recharge cycles in a day without losing overall productivity.-However, it was pointed out that if a vehicle needs to stop to be refueled or recharged by a person, it is not fully autonomous, and autonomous operation might actually put a premium on recharge/refuel time.

○ Maintain or improve powertrain efficiency: More efficient powertrains use less fuel or stored energy, requiring less frequent refueling/recharging.

- Crosscut topics:

- Automation

- powertrain efficiency

- Teaming contacts:

- Brij Singh

- Julie Blumreiter

- Jim Szybist

- Burak Ozpineci

- Zeljko Pantic

- Rural fueling and electrical infrastructure: This barrier overlaps with the barrier posed by low-carbon fuels, but it is more centric to the infrastructure for refueling or electrical charging. Currently, farmers typically have fuel delivered to a holding tank on the farm, and the equipment is refueled on-site. Existing rural electricity distribution infrastructure may not support the charging requirements of electrified farm equipment, and fuel distribution networks may not have sufficient capacity to handle low-carbon fuels in parallel with existing fuels.

- On-site electricity generation and/or storage: Farm-scale microgrids could integrate agrivoltaics or other local electricity generation and energy storage capabilities to eliminate the need for large- 
scale upgrades to the electrical distribution infrastructure to support charging of electrified powertrains.

- Localized fuel production: Small-scale or localized fuel production at the farm, or co-op scale, or as a part of a regional fuel hub could reduce the need to upgrade fuel distribution networks.

- Determination of electric charging scale: Because agricultural equipment typically does not leave the farm, the electric charging capabilities need to be installed on the farms directly and will most likely be for a single user. The scale of the charging infrastructure will be highly dependent on equipment size and charging patterns. It will be additionally dependent on whether battery swapping is feasible. Thus, a total cost of ownership analysis needs to be determined and the analysis must include multiple electrification strategies.

- Portable fueling infrastructure: Lifecycle decarbonized fuels may not be compatible with existing fueling infrastructure on farms. Rather than installing permanent fueling systems that are compatible with a new fuel at the same time that new agricultural equipment is being purchased, it may be possible to rent or purchase a prepackaged, self-contained fueling system (e.g., on a trailer bed).

- Crosscut topics:

- Localized fuel/electricity production

- Teaming contacts:

- Brij Singh

- Julie Blumreiter

- Jim Szybist

- Burak Ozpineci

- Unproven durability of new technologies: New decarbonized powertrain technologies, whether electrified or running on decarbonized fuels, do not have a proven track record. Farmers will prefer to invest in something that they perceive as lower risk.

- Demonstration projects: Demonstrations that are partnerships between industry, academia, and government that run sufficiently long to demonstrate durability of the new technologies could increase confidence.

- Rapid aging: Component tests that emulate field aging would ensure that decarbonized agricultural equipment will meet or exceed the required life expectancy.

- Modular design: Developing modular designs for crucial components (both electrified and decarbonized fuel powertrains) will enable the components to be swapped out rapidly to facilitate repairs without significant downtime.

○ Crosscut topics: tbd

- Teaming contacts:

- Brij Singh

- Julie Blumreiter

- Jim Szybist

- Burak Ozpineci

- Total cost of ownership and high initial investment: Many of the decarbonized equipment options, whether they are powered by electricity or decarbonized fuel, have the potential to be more expensive than current technologies, or have more uncertainty regarding the total cost.

$\circ$ Reducing battery cost: A significant portion of the cost of electrified agricultural equipment is the battery itself. To reduce these costs, it is essential that agricultural equipment leverage the battery cost reductions that are ongoing in the on-road sector.

- Reducing the cost of decarbonized fuel: There is a tax incentive for off-road diesel but not for decarbonized fuel. Changing the incentives to make fuels such as denatured ethanol (E98) less expensive through a tax incentive would reduce the total cost of ownership. Removing 
requirements to blend low-carbon fuels such as ethanol with petroleum derived base fuels could also reduce fuel costs.

$\circ$ Renting vs. owning: The need for agricultural equipment is highly seasonal. Leveraging investments in this equipment with the equipment needs other local operations, such as warehouses, would reduce the costs for individual farms. This could be for the entire piece of equipment, or simply for the battery pack.

- Automation: Automated equipment could offset the costs of advanced powertrains by reducing labor costs.

- Efficiency: More efficient powertrains would reduce consumption of fuel and/or electricity, reducing total cost of ownership.

- Crosscut topics:

- Localized fuel/electricity production

- Automation, powertrain efficiency

- Teaming Contacts:

- Brij Singh

- Julie Blumreiter

- Jim Szybist

- Burak Ozpineci

- Zeljko Pantic

- Lack of lifecycle metrics and regulations: Regulations are currently based on tailpipe GHG emissions rather than lifecycle GHG emissions. There is a recognition that in order to achieve the decarbonization goal, putting all technologies on the same lifecycle GHG regulations is necessary. 



\section{LOW-ENERGY NITROGEN FIXATION}

\subsection{TOPIC 3: NITROGEN CATALYSIS}

Moderator: Gabriel Veith

Scribe: Robert Sacci

\subsubsection{Summary}

The activation of nitrogen and generation of $\mathrm{N}-\mathrm{H}$ bonds account for $\sim 3 \%$ of the world's $\mathrm{CO}_{2}$ emissions (two-thirds for $\mathrm{H}_{2}$ generation and one-third for ammonia production) and continues to grow with increasing food demands and the development of specialty materials. To achieve the economies of scale required for commodity chemicals, the capital costs associated with a Haber-Bosch plant can exceed $\$ 4$ billion (US dollars). This cost, along with inadequate road and pipeline infrastructure, limits economic growth and food security in large parts of the world. Despite the importance of nitrogen catalysis, relatively little effort is devoted to new approaches to activating the $\mathrm{N} \equiv \mathrm{N}$ triple bond beyond optimization of the heterogeneous catalysts used in Haber-Bosch reactors.

Recent advances in water electrolyzers and the potential advent of "free" electrons from renewable sources indicate the potential to disrupt the ammonia market and to generate ammonia in a distributed network with a significantly lower carbon footprint. However, to realize this market, new approaches to conversion of $\mathrm{N}_{2}$ at low temperature and pressure need to be realized to couple with green hydrogen produced on the scale of 1 to $10 \mathrm{~T} /$ day (10 to $100 \mathrm{~T} \mathrm{NH}_{3} /$ day). Lower pressures and temperatures are feasible as evidenced by nitrogenase's ability to reduce $\mathrm{N}_{2}$ to ammonia within a complex metal cage and selective transfer of $\mathrm{H}^{+}$. Participants in the breakout meeting identified several key scientific barriers that need to be addressed through new approaches, complex multidisciplinary teams, and a combination of applied and fundamental science. The following barriers have been identified:

- New approaches to trapping and activating $\mathrm{N}_{2}$. at atmospheric pressure and temperatures

- Coupling "free" electrons with chemical processes at scale.

- New approaches to activating $\mathrm{N}_{2}$.

\subsubsection{Barriers and Solutions}

- In order to efficiently accomplish direct reduction or oxidation of $\mathrm{N}_{2}$, we need new approaches to trapping and activating $\mathrm{N}_{2}$ at atmospheric pressure and temperatures. Nature traps and dissociates $\mathrm{N}_{2}$ using a Mo-Fe complex while mankind uses high pressures and temperatures to trap and activate $\mathrm{N}_{2}$ on a transition metal surface. New advances in synthesis and materials should be evaluated for trapping $\mathrm{N}_{2}$ and activating it for subsequent chemical conversion.

$\circ$ Complex heterogenous structures to trap and activate $\mathrm{N}_{2}$ at standard temperatures and pressures are needed:

- See recent examples of Li-doped zeolites for selective $\mathrm{N}_{2}$ gas adsorption

- Metal-organic-framework materials

- Designer carbon materials to trap $\mathrm{N}_{2}$

- Surfactant, peptide, or complex organic ligands to trap $\mathrm{N}_{2}$

- Complex Mo-Fe catalyst sites mimicking biological processes

- Reagent swing desorption processes to co-locate $\mathrm{N}_{2}$ and $\mathrm{H}_{2}$

- Crosscut topics:

- Simulation, synthesis, and characterization of complex, dynamic nitrogen trapping sites

- Molecular understanding of $\mathrm{N}_{2}$ adsorption structure 
○ Possible teaming:

- Julie Renner, Case Western Reserve University

- Sara Thoi, Johns Hopkins University

- Coupling free electrons to chemical processes. With the advent of low-cost renewable sources of electrons, the challenge becomes how to integrate that source of power with chemical reactors to perform selective reduction of $\mathrm{N}_{2}$ over $\mathrm{H}^{+}$to $\mathrm{H}_{2}$. Current processes produce excessive $\mathrm{H}_{2}$ or are inefficient. A second major challenge is development of the efficient low-overvoltage reduction of $\mathrm{H}^{+}$ to $\mathrm{H}_{2}$ as a green hydrogen source.

$\circ$ Selective reduction of $\mathrm{N}_{2}$ and the production of $\mathrm{N}-\mathrm{H}$ bonds

- Synthetic electrobiology allows for high value chemical and perhaps chiral synthesis

- Control of proton transport on reducing surfaces

- Lack of knowledge regarding high-pressure electrochemistry of $\mathrm{N}_{2}$

- Robust analytical approaches to $\mathrm{NH}_{3}$ production and purity

- High-temperature fuel cells and molten salt reactors

- Crosscut topics:

- Simulation, synthesis, and characterization of $\mathrm{H}^{+}$reduction sites

- Directed synthesis of complex alloy compositions with robust architectures for $\mathrm{H}_{2}$ production - Possible teaming:

- Shelly Minter, University of Utah

- Kathy Ayers, Nel Hydrogen

- New approaches to activating $\mathrm{N}_{2}$. Traditional Haber-Bosch-type reactors activate $\mathrm{N}_{2}$ at elevated temperatures and pressures. Alternative approaches building from developments in power electronics and electrical circuits offer unique opportunities to activate $\mathrm{N}_{2}$ and form reactive chemical species.

- Alternative approaches to the activation of $\mathrm{N}_{2}$

- Plasma chemistry

- Radio-frequency power/microwaves and optical activation

- Electrodes

- Mechanochemistry

- bioelectrochemistry

- Crosscut topics:

- Radioactive nitrogen is generated using klystrons at the SNS. Can this be explored and optimized?

- How do you selectively reduce $\mathrm{N}_{2}$ over $\mathrm{H}^{+}$?

○ Possible teaming

- Jingguang Chen, Columbia University

- Carsten Sievers and Marta Hatzell, Georgia Tech

- Jason Hicks, Notre Dame

- Karthish Manthiram, CalTech

- Direct oxidation of $\mathrm{N}_{2}$. Ammonia is traditionally converted to nitric acid species through the Ostwald process. Can this be changed to improve efficiency?

Alternative approaches to the activation of $\mathrm{N}_{2}$

Plasma chemistry

Radio-frequency power/microwaves and optical activation

Crosscut topics:

- Thirteen years ago, members of the battery community at the national laboratories joined together to form a new meeting series entitled "Beyond Lithium Ion Batteries." The meeting brought together hundreds of researchers from around the world to discuss the next generation of energy storage. We propose a similar meeting series on the activation of $\mathrm{N}_{2}$. 
Such a meeting would be an opportunity to engage the community, build partnerships, and educate the DOE on progress in this area. This would build on the 2016 DOE-BES roundtable report "Sustainable Ammonia Synthesis - Exploring the scientific challenges associated with discovering alternative, sustainable processes for ammonia production." 



\section{REFERENCES AND LINKS}

International nitrogen initiative:https://initrogen.org/

Introduction Bio Slides:

https://drive.google.com/drive/folders/1WBg2LYTjBjpDUB5jQVf7GaEJvEuZ4Dga

\section{LUCAS:}

https://esdac.jrc.ec.europa.eu/projects/lucas

ORNL press release on September 21:

https://www.ornl.gov/news/agricultural-decarbonization-gets-new-emphasis-ornl

Powell Center N Consortium:

https://www.usgs.gov/centers/powell-ctr/science/novel-multi-scale-synthesis-nitrogen-fixation-rates-anddrivers-across?qt-science_center_objects=0\#qt-science_center_objects

Nutrient Network:

https://nutnet.org/

OpTIS tillage and cover database:

https://www.ctic.org/optis

QuantumPro:

https://quantumprot.com/

QIO:

https://qio.ai/

SoilHealthDB:

https://data.nal.usda.gov/dataset/data-database-global-soil-health-assessment

World Soil Information Service Soil Profile Database:

https://www.isric.org/explore/wosis

"Sustainable Ammonia Synthesis - Exploring the scientific challenges associated with discovering alternative, sustainable processes for ammonia production." DOE-BES Roundtable Report, February 2016. https://sc.osti.gov/-/media/bes/pdf/reports/2016/SustainableAmmoniaReport.pdf 



\section{APPENDIX A. AGENDA}

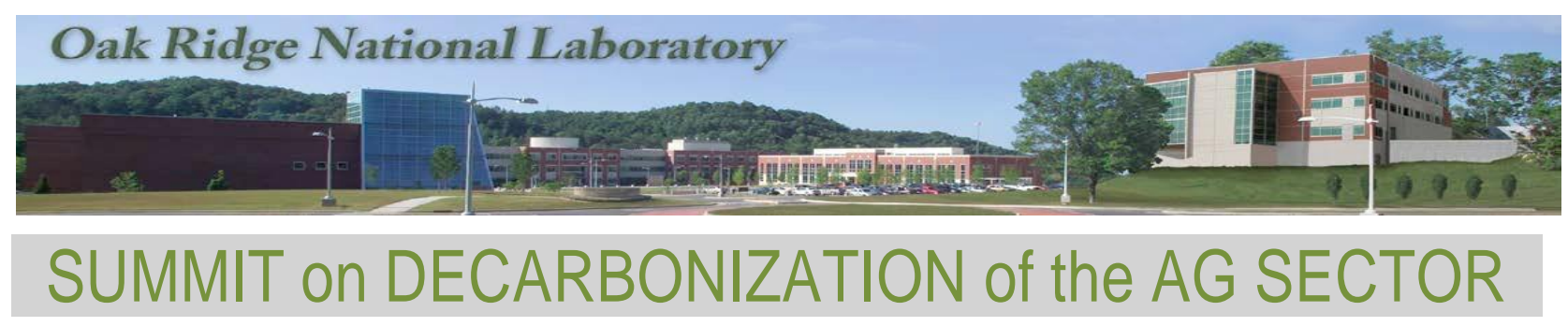

Date: September 21- 222021

Convenors: Brian Davison, Jerry Tuskan, Robert Wagner

Agenda Day 1 September 21

(Current as of Sept. 21)

\begin{tabular}{|c|c|c|c|c|}
\hline 10:00 AM & \multicolumn{2}{|l|}{ Welcome } & Gerald Tuskan & ORNL \\
\hline $10: 10 \mathrm{AM}$ & \multicolumn{2}{|c|}{$\begin{array}{l}\text { DOE role and vision in the Decarbonization of } \\
\text { the Agriculture Sector }\end{array}$} & Valerie Reed & US DOE, EERE- BETO \\
\hline 10:20 AM & \multicolumn{2}{|c|}{ Purpose of Summit } & Brian Davison & ORNL \\
\hline 10:30 AM & \multicolumn{2}{|c|}{ Overview Carbon \& Climate Impacts in $\mathrm{Ag}$} & Gunars Platais & Colorado ST. Boulder \\
\hline $11: 00 \mathrm{AM}$ & Topic 1: & Soil Health, $\mathrm{C} / \mathrm{N}$ bio focus & Francesca Cotrufo & Colorado State Univ. \\
\hline $11: 20 \mathrm{AM}$ & Topic $1 \mathrm{~A}$ : & Decision Support Tools & A J Kumar & Indigo Ag \\
\hline $11: 30 \mathrm{AM}$ & Topic $1 \mathrm{~B}$ : & $\mathrm{N} 2 \mathrm{O}$ - Cycling & Chuck Rice & Kansas State Univ. \\
\hline $11: 40 \mathrm{AM}$ & Topic $1 \mathrm{C}$ : & Soil Health \& Microbials & Maria Mooshammer & Trace Genomics \\
\hline $11: 50 \mathrm{AM}$ & Topic 1: & Soil Health QA & Panel & \\
\hline 12:00 PM & \multicolumn{2}{|l|}{ Break } & & \\
\hline $12: 10 \mathrm{PM}$ & Topic 3: & $\begin{array}{l}\text { Nitrogen production, } \\
\text { Challenge needs in new catalysis }\end{array}$ & Jingguang Chen & Columbia Univ. \\
\hline $12: 30 \mathrm{PM}$ & Topic $3 \mathrm{~A}:$ & $\begin{array}{l}\text { Nitrogen production } \\
\text { new catalysis }\end{array}$ & Kathy Ayers & Nel Hydrogen \\
\hline 12:40 PM & Topic 3 B: & Nitrogen bio-fixation & Lisa Tiemann & MSU GLBRC \\
\hline 12:50 PM & Topic 3: & Nitrogen production QA & Panel & \\
\hline 1:00 PM & Topic 2: & $\begin{array}{l}\text { Agriculture equipment \& } \\
\text { operations-overview }\end{array}$ & Jahmy Hindman & John Deere \\
\hline 1:20 PM & Topic 2 A: & Precision agriculture & Scott Shearer & Ohio State Univ. \\
\hline 1:30 PM & Topic 2 B: & Combustion and fuels & Julie Blumreiter & Clearflame \\
\hline 1:40 PM & Topic $2 \mathrm{C}:$ & Electrification of $\mathrm{Ag}$ vehicles & Burak Ozpineci & ORNL \\
\hline 1:50 PM & Topic 2: & Agriculture QA & Panel & \\
\hline 2:00 PM & Instruction & oreakouts & Davison/Jones & \\
\hline 2:05 PM & $\begin{array}{l}\text { Topic Breal } \\
\text { Introductior } \\
\text { Rank Barric } \\
\text { Brainstorm }\end{array}$ & $\begin{array}{l}\text { Sessions } \\
\text { min. Identify Barriers } 25 \mathrm{~min} \\
0 \mathrm{~min} \\
\text { Possible Solutions } 15 \mathrm{~min}\end{array}$ & & \\
\hline 3:05 PM & Break & & & \\
\hline 3:15 PM & Breakout R & t 5 minutes each group & & \\
\hline 4:05 PM & Day 1 Wrap & / Adjourn & Davison / Tuskan & ORNL \\
\hline
\end{tabular}




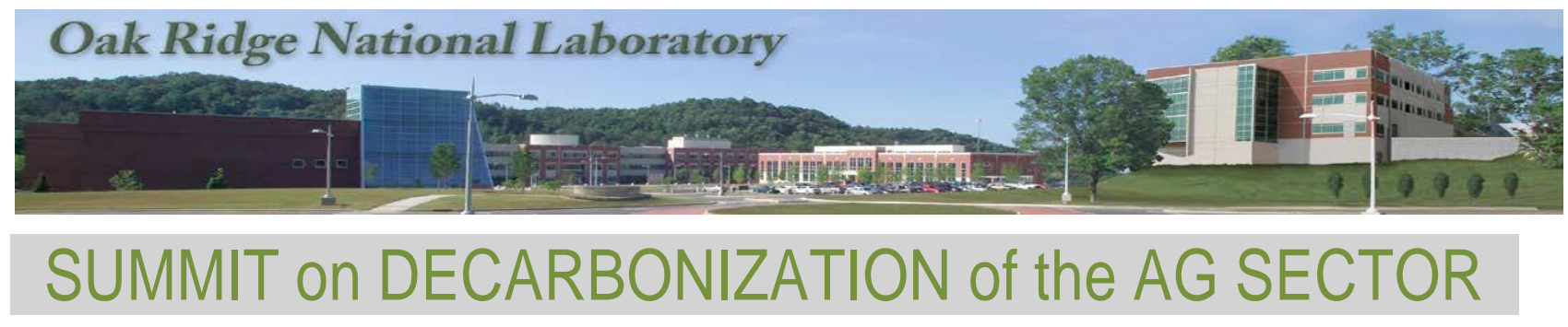

Date: September 21- 222021

Convenors: Brian Davison, Jerry Tuskan, Robert Wagner

Agenda Day 2 September 22

\begin{tabular}{|l|l|l|l|}
\hline 10:00 AM & Day 2 logistics and charge & Davison / Tuskan & ORNL \\
\hline 10:05 AM & $\begin{array}{l}\text { Crosscut opportunities: four 10-min talks } \\
\text { illustrate opportunities \& portfolios may } \\
\text { include AI/ML, GIS/sensors, assessment } \\
\text { models, Earth System models }\end{array}$ & $\begin{array}{l}\text { Peter Thornton Ben } \\
\text { Brown } \\
\text { V. Sudhakar Kaiyu } \\
\text { Guan }\end{array}$ & $\begin{array}{l}\text { ORNL } \\
\text { Lawrence Berkeley Lab } \\
\text { Schlumberger (SLB) } \\
\text { UIUC }\end{array}$ \\
\hline 10:45 AM & Q \& A Moderated Panel & & \\
\hline 11:00 AM & $\begin{array}{l}\text { Topic Breakout Sessions: } \\
\text { Discuss potential solutions to barriers \& } \\
\text { Path forward } \\
\text { Review revise barriers 10 min } \\
\text { Expand list of possible solutions 20 min } \\
\text { Link needed crosscuts 15 min } \\
\text { List potential PoC and gaps. 15 min } \\
* \text { Same groups from day 1 }\end{array}$ & \\
\hline 12:00 PM & \multicolumn{1}{|c|}{ Break minutes each group } & & \\
\hline 12:15 PM & Breakout Report & & \\
\hline 1:15 PM & Discussion & & \\
\hline $1: 40$ PM & Define actions \& next steps & & \\
\hline $2: 00$ PM & Day 2 Wrap-up / Adjourn & Davison / Tuskan & ORNL \\
\hline
\end{tabular}




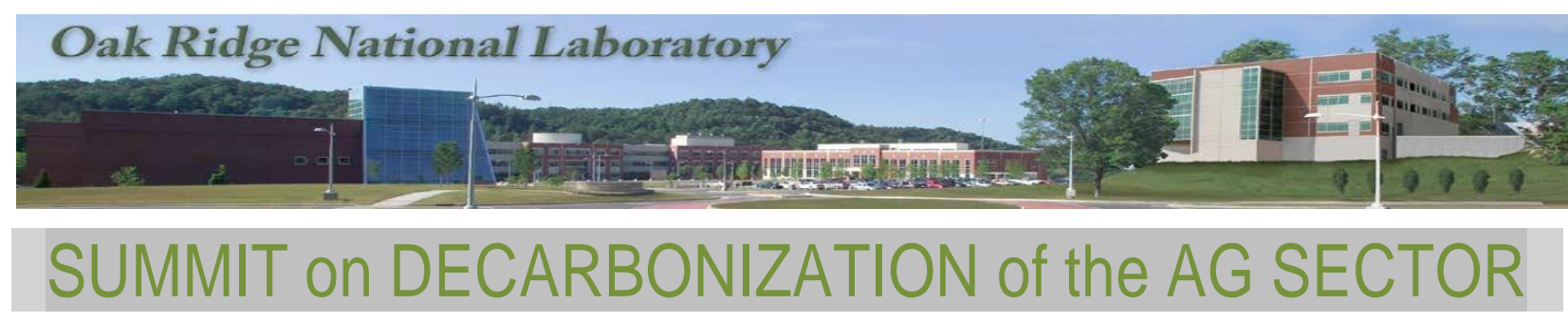

\section{Breakout Session Topics:}

1a: Soil carbon dynamics \& manipulation Chris Schadt, Moderator, Jessica Moore, scribe MIRO

1b: Improving Nitrogen use efficiency, Melissa Cregger moderator, Matt Craig, scribe MIRO

1c: Soil Measurement, monitoring \& verification, John Field, moderator; Maggie Davis, scribe MIRO

$\underline{\text { 2a: Precision Ag, Erin Webb moderator, Esther Parish scribe }}$ MIRO

2b: Equipment power and propulsion; Josh Pihl, moderator; Jim Szybist, scribe MIRO

3: Nitrogen catalysis Gabriel Veith, moderator; Robert Sacci, scribe MIRO 



\section{APPENDIX B. PARTICIPANTS}

Topic 1a: Soil Carbon Dynamics andManipulation

Moderator: Chris Schadt (ORNL)Scribe: Jessica Moore (ORNL) Attendees:

Sean Schaeffer (Univ. TN) Sindhu Jagadamma (Univ. TN)

Francesca Cotrufo (Colorado State)Melanie Mayes (ORNL)

Ziyi Li (UIUC)

Udaya Kalluri (ORNL) Shawn Campagna (Univ. TN)

Matthew Ricker (NC State Univ)Jerry Tuskan (ORNL)

Jianwei Li (TN State Univ)Renae Speck (ORNL)

Kelly Zering (NC State Univ)

Topic 1b: Improving Nitrogen Use Efficiencyand Soil Nitrogen Cycling

Moderator: Melissa Cregger (ORNL)Scribe: Matt Craig (ORNL) Attendees:

Ben Sulman (ORNL)

Lisa Tiemann (MI State Univ)Joshua Fu (Univ TN)

Peter Thornton (ORNL)

Vasudhaven Sudhakar (Schlumberger)Dafeng Hui (TN State Univ)

Lexuan Ye (UIUC)

Topic 1c: Soil Measurement, Monitoring andVerification

Moderator: John Field (ORNL)Scribe: Maggie Davis (ORNL) Attendees:

Dan Ricciuto (ORNL)Ziqi Qin (UIUC)

Art Wiselogel (DOE/BETO)

Maria Mooshammer (Trace Genomics)Elizabeth Herndon (ORNL)

Topic 2a: Precision Ag

Moderator: Erin Webb (ORNL)Scribe: Esther Parish (ORNL) Attendees:

Angela Bowman (John Deere \& Co)

Ben Brown (Arva Intelligence and LBNL)Nicke Goeser (ASABE)

Dan Jacobson (ORNL) Chelin Li (DOE-BETO)

Gunars Platais (Sustainability Innovation Lab atColorado, the Univ Colorado, Boulder)

Scott Shearer (Ohio State)

Topic 2b: Agriculture Equipment Power andPropulsion

Moderator: Josh Pihl (ORNL)

Scribe: Jim Szybist (ORNL)

Burak Ozpineci (ORNL)

Julie Blumreiter (Clear Flame EngineTechnologies)

Robert Wagner (ORNL)Tim Theiss (ORNL)

Michael Weismiller (DOE-EERE-VTO)Brij Singh (John Deere)

Topic 3: Nitrogen Catalysis

Moderator: Gabriel Veith (ORNL) 
Scribe: Robert Sacci (ORNL)

Shelly Minteer (Univ Utah) Andrew Sutton (ORNL) Zili Wu (ORNL)

Timmy Ramirez Cuesta (ORNL)Kathy Ayers (Nel Hydrogen)

Other registered attendees(for presentations)

Valerie Reed (USDOE EERE BETO)

A J Kumar (Indigo Ag)

Chuck Rice (Kansas State Univ.)

Jingguang Chen (Columbia Univ.)

Jahmy Hindman (John Deere)

Peter Thornton (ORNL)

Kaiyu Guan (UIUC)

David Sholl (GaTech/ORNL)

Zeljko Pantic (NCSU)

Benjamin Mintz (ORNL)

Helga Dögg Flosadóttir (Atmonia)

Nichole Fitzgerald (USDOE-EERE-BETO)

Hilary Brawner (Schlumberger)

Cathy Ronning (USDOE-SC-BER)

Shing Kwok (USDOE-SC-BER)

\section{Summit Report Writing Team:}

Moderators, scribes, Carmen Jones (ORNL),John Wagner (ORNL), Walter Koncinski Jr (ORNL), Udaya Kalluri (ORNL) and Brian Davison (ORNL) 


\title{
APPENDIX C. DRAFT WHITE PAPER FROM ORNL-JULY 2021
}

\author{
DECARBONIZATION OF THE U.S. AGRICULTURAL SECTOR
}

ORNL White Paper June 13, 2021 (revised July 2021)

\begin{abstract}
Gerald Tuskan, Brian Davison, Melanie Mayes, John Field, Steven Ward, Udaya Kalluri, Chris Schadt, Elizabeth Herndon, Dan Jacobson, Robert Wagner, Erin Webb, Gabriel Veith, Dan Ricciuto, Ben Sulman
\end{abstract}

The U.S. agricultural ecosystem offers an opportunity to contribute to the circular carbon economy and ultimately the decarbonization of the atmosphere. This opportunity spans the mission space of both the USDA and US DOE.

Magnitude and impact: The food system accounts for as much as 1/3 of total global greenhouse gas (GHG) emissions through land use change, agricultural emissions of methane $\left(\mathrm{CH}_{4}\right)$ and nitrous oxide $\left(\mathrm{N}_{2} \mathrm{O}\right)$, production of fertilizers and other on-farm inputs, as well as energy use on the farm and for the transport, processing and distribution of agricultural products (Crippa et al. 2021). The U.S. has over 900 million acres of agricultural quality land, with approximately 420 million acres in commercial production. Agricultural food production uses approximately 1,714 trillion Btu of energy annually and this only accounts for on-site consumption and not the cost of manufacturing and transporting of fertilizers, farm implements and various other consumables.

The decarbonization of agriculture will require approaches both immediate and long-term to decrease fossil energy inputs, reduce emissions and increase sequestration. The agriculture sector has potential to immediately impact decarbonization by implementing known improved practices that reduce $\mathrm{CH}_{4}$ and $\mathrm{N}_{2} \mathrm{O}$ emissions, reduce energy use and sequester carbon (C). Moreover, the remaining difficult-to-abate $\mathrm{CH}_{4}$ and $\mathrm{N}_{2} \mathrm{O}$ emissions necessitate Carbon Dioxide Removal (CDR) — as known as "negative emissions"- to achieve climate neutrality (Rockström et al. 2016). The agricultural sector may achieve CDR through:

1. widespread adoption of current best management practices (e.g., reduced tillage intensity, cover cropping) that build soil organic matter and sequester carbon,

2. frontier methods that increase the rate of soil carbon sequestration (e.g., increased root allocationand recalcitrance, perennialization, biochar application) and

3. bioenergy with carbon capture \& storage (BECCS) or other C-negative bio-based systems,

which can offset remaining emissions in this and other sectors (Jansson et al. 2010; National Academies of Sciences, Engineering and Medicine 2019; Paustian et al. 2019; Energy Futures Initiative 2020). For example, the use of enhanced Agricultural Soil Management could save $3 \mathrm{GT} \mathrm{CO}_{2} / \mathrm{y}$ at an estimated cost of $\$ 0-50 / \mathrm{T} \mathrm{CO}_{2}$. The future development and deployment of a near-term Bioenergy with Carbon Capture and Storage (BECCS) could capture 3-15 GT CO $/$ y at an estimated cost of $\$ 100-200 / \mathrm{T} \mathrm{CO}_{2}$. In the longerterm, the development and deployment of improved plants for soil sequestration combined with BECCS could capture another 5-8 GT C/y for the next 50 years.

Strategy: Implementing changes in the agricultural sector will contribute to both enhanced natural processes as well as an expansion of the agro-industrial bioeconomy. Positive impacts on carbon flows in agriculture can be grouped to decarbonize inputs, increase carbon sinks and increase sustainable carbon outputs.

Manipulation of the agricultural ecosystem (e.g., tillage, soil amendments and livestock feed additives) to increase soil organic carbon (SOC) storage and decreased soil GHG emission, increased crop nitrogen-use efficiency to decrease nitrogen input and increase crop resilience via agricultural practices, with improved 
plant varieties and designed plant-microbiome systems, will be required. Research efforts to decarbonize the agricultural sector inputs include reduction of fossil energy in farm equipment (heavy duty equipment) via electrification, on-site biofuels/biopower production, increased operational efficiency (lower net energy via precision agriculture) and the replacement of Haber-Bosch nitrogen fertilizer production.

Some of these approaches could be implemented today under policy incentives. For example, precision agriculture and other farming practices (i.e., no till, cover crops, etc.) could be used now as incentivized agricultural management practices to decrease fertilizer and water inputs and increase soil organic carbon. However, most of these approaches will require substantial technological innovations which creates opportunities and presents challenges. Both immediate and long-term implementation will require modeling and assessment activities to validate the impact for policy and valuation.

From a U.S. DOE perspective, research activities could focus on three areas where DOE (and ORNL) has many years of experience and in some cases represents world leading research. These three foci are: soil health and carbon sequestration, implement and vehicle efficiency and electrification and next generation nitrogen economy. Initially Teams have been formed from within ORNL to outline future directions and research opportunities. Researchers from other DOE labs, as well as Academic partners, are being actively recruited to strengthen the research team in each foci. These three research areas -- 1) Soil Health and Carbon Sequestration, 2) Vehicle and Propulsion System Efficiency and 3) Next Generation Nitrogen Economy, are presented below.

\section{C.1 Soil Health and Carbon Sequestration (Focus Area Leads: John Field and Steven Ward)}

Soil health in the context of agriculture is the long-term ability of soil to sustain ample productivity of diverse crops while maintaining or increasing its capacity to provide broader ecological benefits, e.g., carbon storage and water quality regulation. Soil organic matter - the decomposed and stabilized remains of plant tissue and microbial biomass - is a central element of soil health affecting crop productivity, water retention, water quality and the overall resilience of farmland. Increasing soil organic matter is also a promising means of CDR in which carbon originally fixed from the atmosphere by plants is stored in the form of soil organic carbon (SOC). There is 2-3X more carbon in SOC than in the atmosphere, despite the fact that soils have lost between 80 and $150 \mathrm{Gt} \mathrm{C}$ to the atmosphere since 1850 due to land use change and intensive agricultural management (Sanderman et al. 2017). Best management practices and other SOCbuilding agricultural technologies can re-sequester lost soil $\mathrm{C}$ while enhancing soil health and ecosystem services, contributing to food and energy security resilience.

Broadly, increase soil health will require efforts in SOC assessment and in improved methods to enhance SOC.

\section{C.1.1 Foundational Soil Organic Carbon Assessment}

The agricultural industry is focused on the rapid development of methodologies for including SOC in carbon trading schemes. However, despite the importance of SOC to both agricultural productivity and climate there remain significant limitations to SOC measurement and monitoring. SOC is characterized by a high degree of spatial heterogeneity and the large size of the SOC pool means that climatically relevant sequestration corresponds to only relatively small changes in soil $\mathrm{C}$ concentration (e.g., $0.4 \%$ per year; Minasny et al. 2017); together these factors present a significant detection problem. The gold standard for SOC measurement is soil core drilling followed by laboratory combustion-based $\mathrm{C}$ measurement, though these are laborious and expensive-particularly for deep soil cores measuring SOC under deep-rooted perennial crops including biomass feedstocks. These limited available soil core measurements are routinely supplemented with statistical and process-based modeling, though widely-accepted modeling standards with rigorous data-model integration and uncertainty quantification are lacking. Concerns around the 
accuracy of SOC estimation contribute to the limited inclusion and value of SOC-based credits in carbon trading schemes or in policy implementation.

While the agricultural industry is focused on the rapidly developing transactional side of SOC-based carbon trading, the scientific community is under increased pressure to develop improved methods for SOC measurement and monitoring and to quantify the capacity of different SOC sequestration modalities. ORNL is well positioned to be a national leader in soil health and SOC measurement, modeling and biotechnology for climate security. Relevant existing capabilities and areas of expertise at the lab include high throughput phenotyping, molecular science, scaled remote sensing analysis and exploitation, bioenergy research, genetic and microbial sequencing, soil biogeochemistry, sensor design and manufacturing and synthetic biology. This includes basic soil science research supported by the DOE Biological and Environmental Research (BER) program, as well as expertise around the SOC performance of bioenergy systems supported by the DOE Bioenergy Technologies Office (BETO).

In addition to these core scientific and manufacturing capabilities, ORNL benefits from its position as a neutral party outside of the agriculture industry or regulatory environments. ORNL has the experience andability to conduct national-scale studies and sits at the nexus of Academia, Industry and Government. These assets help to establish ORNL in a position of trust and authority that will be key to the successful establishment of a foundational SOC assessment for the US agricultural sector. Given the size and complexity of the soil health challenge, ORNL will have to partner with other national laboratories with interests in this area (e.g., Lawrence Berkeley National Laboratory, Pacific Northwest National Laboratory), as well as leading agriculture-focused land-grant universities (e.g., the University of IllinoisUrbana-Champaign, Purdue University, Iowa State University, Virginia Tech, North Carolina State University), leading industry partners (e.g., Bayer, Corteva, BASF, Nori, Indigo) and other relevant government agencies (e.g., USDA, EPA, USFWS). Approaching this problem at a national scale to establish an unbiased set of standards requires the development of:

\section{C.1.1.1 Benchmark SOC Datasets}

A robust understanding of current-day baseline SOC levels is a critical prerequisite for understanding the performance of soil carbon sequestration programs in terms of potential capacity, soil interaction with plants, relationships with macro/micro-nutrients and soil response to changes in management practices over time. This requires compiling existing soil core samples and SOC measurements into unified, machinereadable databases and then supplementing with additional soil core sampling in high-priority areas. Such a resource is also a critical component to developing and validating improved predictive SOC models. Specific relevant research activities in this area are to:

- Define required spatial coverage of measurement for adequate assessment of SOC and soil nitrogen

- (N) stocks.

- Compile robust soil core \& SOC measurement datasets as a function of soil types, biome, spatial variability, land use history, etc.

- Build and validate improved predictive models based on measured core data, utilizing data-model integration techniques to quantify model uncertainty.

- Consider the transport and immobilization of SOC and N from surface soils through watersheds. 


\section{C.1.1.2 Novel SOC Measurement, Testing \& Modeling Methods}

Development of a nationwide SOC benchmark should also include the development of novel methods, sensors and validation methods at scales never attempted in previous studies. Improved SOC measurement could rely on higher-throughput SOC sampling \& processing methods, in-situ sensing of soil electrical and optical properties and/or hyperspectral remote sensing. Such techniques would benefit from further refinement of the theoretical basis of different SOC stabilization mechanisms (e.g., Lavallee et al. 2020). Such research efforts should be geared directly towards industry applications in support of nascent SOC trading markets. Relevant research activities are to:

- Define appropriate temporal and depth scales of soil core collection relevant for SOC validation sampling.

- Understand plant properties, mechanisms, genetics and genomic architectures influencing amount,type and fate of carbon allocated belowground, as well as the mechanisms of soil carbon storage in different forms (e.g., particulate organic matter, mineral-associated organic matter), sufficiently toenable credible predictive capability.

- Understand the contributions of edaphic properties (e.g., moisture, soil type, climate) on observed SOC stabilization; Establish "right model for the right location" framework.

- Develop high throughput methodologies for in-situ and in-lab spectroscopy, chemical analyses and imaging techniques suitable for larger-scale SOC \& N data collection.

- Advance data-model integration to leverage large volumes of data collected via in situ measurement or remote sensing to better guide and constrain predictive models.

Decarbonization of the ag economy has at least two aspects which require integration with global and regional models and modeling to accomplish. First, agricultural production is energy-intensive and necessarily dispersed, generating fossil fuel emissions on the field, in transit and during processing. Part of those emissions comes from farm and transport vehicles and part comes from fertilizer production, irrigation (pumping) and energy requirements for processing raw farm goods. Life cycle analysis driven by intensive measurement can provide good estimates of the emissions associated with a given field through an annual cycle, but extrapolation of such estimates to regional and national scales requires a spatial modeling capability integrated with remote sensing and producer databases. A second and more nuanced aspect of agricultural carbon footprints has to do with gross and net exchanges of carbon among the atmosphere, growing vegetation and soil. Models are required to account for both long-term carbon loss from soils due to initial land cover conversions and traditional tillage practices and long-term carbon accumulation in soil associated with management practices intentionally aimed at sequestration. These models must also account for the interactions of soil carbon, plant growth, soil structure and nutrient dynamics. Management practices that optimize crop yield are not necessarily compatible with the objectives of carbon net-neutrality and a predictive understanding of the dynamics of the nitrogen cycle in particular is crucial to making good long-term estimates of system-level net nitrogen and carbon flux. Research goals in linking to global and regional models are discussed under the Nitrogen Economy (Section 3.3).

\section{C.1.2 New Methods \& Technologies for Enhancing SOC Potential}

A robust national program should move beyond current SOC best management practices and pursue frontier methods for enhanced sequestration based on biotechnology, plant breeding and bioenergy solutions. Initial targets could include bioenergy, cover, or forage crops, which have minimal regulatory barriers to market for genome-edited strains as compared to food crops. Select approaches that improve SOC outcomes 
without compromising yields could potentially be further developed in annual food crops as well (Paustian et al. 2016). Such work should be targeted to developing the biological, mechanical and chemical basis for implementation in the agricultural industry. Relevant research activities are to:

- Select or engineer for belowground plant traits that optimize SOC sequestration without affecting plant health or aboveground yields. Specific traits could include increased root biomass, lignin content and $\mathrm{C} / \mathrm{N}$ ratio; enhanced secretion of recalcitrant root carbon secretions; or enhanced labile secretions and volatiles taken up by the plant root microbiome (particularly those targeted at fungal communities). Key genes and Genetic regulators have already been discovered for several of these traits (e.g., drought tolerance, lignin content) and appear to have effects on other plant species. There are successful programs for gene discovery in non-model feedstocks (i.e., poplar). Our ability to validate these targets is a challenge but it is rapidly improving by recent genetic tools like CRISPR/Cas9.

- Develop microbial or mineral soil amendments that enhance plant photosynthesis and C sequestration through altered decomposition potential, enhanced weathering, $\mathrm{N}$ fixation or denitrification, or mobilization of phosphorous and key micronutrients. Microbiome amendments are already known to increase yield and nitrogen uptake (e.g., Jesse Labbe's SAFE - Symbionts to Advance Food and Energy, PIVOT Bio)

- Engineer carbon-rich soil amendment coproducts from bioenergy conversion (e.g., biochar, highlignin fermentation residues).

- Develop methods for bioenergy landscape design and optimization to guide the integration of bioenergy crops into agricultural landscapes with minimal disruption to existing production or areas of high conservation value. This could include genome-wide association time-series (GWATS) methods identifying genotype by environment $(\mathrm{GxE})$ associations underlying plant success at marginal sites and techno-economic analysis.

These efforts will require accelerated laboratory work in gene discovery and validation as well as wellmonitored field studies and linked modeling.

\section{C.2 Agricultural Equipment and Operations Efficiency (Focus Area Leads: Robert Wagner and ErinWebb)}

Agriculture utilizes significant fossil fuel (and some limited biodiesel) in transportation and for heavy duty farm machinery. Fossil input in this area can be improved by precision agriculture and other efficiencies, by low carbon fuels and associated engines and by vehicles electrification.

\section{C.2.1 Precision Agriculture and Efficient Operations}

\section{C.2.1.1 Remote Sensing and Spatial/Temporal Field Management - Erin Webb}

Intensification of agriculture to meet the food, fiber and energy needs for a rapidly expanding global population while minimizing environmental impacts requires precision management of crops. Precision crop management - giving each plant exactly what it needs and no more - avoids excess fertilizer, chemical and water use, it saves energy and minimizes soil disturbance. Individual plant management over large field areas requires advancement in sensing to assess plant condition, biophysical modeling to inform management decisions and machine development for precise treatment (e.g., chemical application) of individual plants. Continued development of advanced sensing and imaging technologies deployed by satellites, drones, or on agricultural machinery will enable assessment of single plants to identify pest or 
disease stress and to determine specific needed management inputs such as fertilizer and water. In the nearterm, coupling this field, soil, weather and crop data with real-time biophysical models can guide producers in developing day-to-day operational plans and routing and scheduling equipment to maximize efficiency. In the long-term, this leads to advanced AI decision-making and automation of field operations. Advances in sensing and modeling will not only guide farm management decisions, but they can also lead to rapid crop phenotyping for identifying desired traits in large crop populations to enable deployment of crop varieties with enhanced resilience and sustainability traits.

\section{C.1.2.1 Connected and Autonomous Systems (24/7 operations) - Burak Ozpineci}

Depending on the functions of the vehicles they can be used in a connected and/or automated fashion allowing 24/7 operation. Vehicles can operate in parallel to increase the efficiency of sowing seed, harvesting, etc. to increase the efficiency of farming.

- Instead of designing large vehicles with larger storage, smaller vehicles (ground drones) can be designed to run in a coordinated fashion to do the work in a shorter time and more efficiently. With multiple vehicles running at the same time, the work would still continue while one or two vehicles travel to charging locations and charge autonomously.

- Air drones can also be connected with the ground drones to coordinate the spatial/temporal field management. With some of the thick crop, air drones would not be able to sense the ground level status. Small ground drones can travel under the crop canopy for sensing ground, soil and root growth status.

- Another function of these ground drones could also be detecting weeds and zapping them with lasers without introducing chemicals into the ground. This approach would also eliminate the need for tilling which would increase the overall farming efficiency and would also keep the carbon in the ground to be used by the crop.

\section{C.2.2 Local Low Carbon Fuel Production and Engine Efficiency}

The rapid projected electrification of the light-duty fleet will reduce the demand for gasoline and ethanol for transportation. Ethanol is by far the largest volume biofuel in the US. Ethanol production from corn starch, which is currently the dominant path, can reduce $\mathrm{CO}_{2}$ emissions by more than $50 \%$ compared to gasoline on a lifecycle basis and ethanol. Ethanol produced from cellulose is a $2^{\text {nd }}$ generation biofuel with even larger $\mathrm{CO}_{2}$ decreases. Additionally, methanol has many of the same fuel properties and material compatibility challenges as ethanol. Methanol is a leading candidate for fuels produced from $\mathrm{CO} 2$ synthesis (e-fuel) and can also be produced from biomass through numerous routes.

As a result, there are numerous potential pathways for both methanol and ethanol to be deeply decarbonized fuels on a lifecycle basis and for them to be produced locally at the farming community scale. However, farm equipment typically uses diesel engines, which are not compatible with ethanol and methanol due to the fuel property requirements. Transforming agricultural equipment to operate on these deeply decarbonized fuels will both reduce the $\mathrm{CO}_{2}$ emissions and ensure that our largest volume biofuel produced in the U.S. continues to have a path for utilization.

\section{C.2.2.1 Stoichiometric SI MD/HD Agriculture Machinery - Robert Wagner, Jim Szybist}

Stoichiometric spark ignition (SI) engines have not historically had a significant role in the agriculture sector due to lower torque and lower efficiency as compared to diesel engines. While these are challenges, stoichiometric SI engines have generated increasing industry interest due two major advantages: 1) use of 
comparably simple three-way catalyst technologies to simultaneously address emissions of NOx, nonmethane hydrocarbons and carbon monoxide and 2) higher exhaust temperatures which ensure catalyst activity over most of the duty-cycle. While SI engines have the potential to provide an economical pathway to meeting emissions regulations, their lower efficiency, lower torque and specific power density all must be addressed to meet the demands of the agriculture industry. Potential areas of research include:

- Long-stroke engine architectures for reduced heat transfer, increased turbulence and higher EGR rates for torque and efficiency approaching that of diesel engines.

- High EGR dilution combustion strategies to enable higher compression ratio and increasedefficiency with reduced engine-out emissions.

- Hybrid electric powertrains for "torque-shaving" and reduced low-load engine operation, allowing conventional SI engines to meet the torque demands of MHDVs and bring overall drive-cycle efficiency closer to parity with diesel engines.

\section{C.2.2.2 Mixing Controlled Combustion with Ethanol and Methanol}

Jim Szybist, Robert Wagner Mixing controlled combustion is the process by which diesel engines operate and has several inherent advantages over stoichiometric SI combustion, namely low-speed torque which is required for some farm operations and improved efficiency due to the fuel-lean operation. While ethanol and methanol have fuel properties that are largely contrary to the needs of a mixingcontrolled engines, there are numerous available technologies in the early stages of research and development that could enable them to be used. Potential areas of research include:

- Gasoline compression ignition with methanol and ethanol, enabled by high compression ratios, advanced fuel injection and advanced valve strategies for residual trapping.

- Pre-chamber technologies that can effectively pre-heat the combustion chamber to enable mixingcontrolled combustion with ethanol and methanol.

\section{C.2.2.3 Hybridization of Agriculture Machinery - Robert Wagner, Jim Szybist}

Hybridization of MHDVs is not in widespread use but has the potential to enable high efficiency, low emissions engine technologies and emissions control systems which currently are not well suited for engineonly powertrains. For example, some promising engine technologies and emissions controls systems are not sufficiently robust or effective across the speed-load demands of an engine-only powertrain but have very high performance over a smaller operational range or under less transient conditions. Hybridization could enable many approaches including right-sized engines, start-stop technologies, electrification of engine components, electrically heated catalysts and unconventional combustion modes as well as augment transient operation which is a major source of emissions. Potential areas of research include:

- Identify levels of hybridization based on drive-cycles of interest for specific agriculture applications.

- Full electric operation under low load operations to eliminate engine emissions when exhaust temperatures would normally be too low for effective emissions control.

- Hybridization to meet high power requirements and downsize engines and associated emissions control systems. 


\section{C.2.2.4 Net-zero Carbon Fuels - Jim Szybist, Robert Wagner}

Low and net-zero carbon fuels are critical to the decarbonization of the agriculture sector with an additional opportunity for regional processing and availability. Opportunity research areas include the impact of low or net-zero carbon fuels on engine efficiency and emissions, emissions controls, start/re-start and transient operation.

- Biofuels (e.g., those identified by DOE Co-Optima initiative) to enable higher compression ratio SI engines for higher torque and efficiency approaching that of diesel engines and for enabling advanced compression ignition engine. This includes blends and full substitution.

- Ammonia as a fuel for CI and compression ignition engines due to local availability as a fertilizer.

\section{C.2.3 Vehicle Electrification}

\section{C.2.3.1 Agriculture-Specific Opportunities-Burak Ozpineci}

Electrifying Ag-vehicles will require charging them on-site using renewable energy and/or on-site energy storage. It is important for these vehicles to either run all day with a large battery or have fast recharging capabilities located close to where they are operated.

- On-site generation using renewables: Solar panels or small wind turbines can be used for energy generation to power the electrified Ag-vehicles and for sending power back to the grid increasing the utilization of the land since typically it stays empty for close to nine months a year. An interesting challenge to study would be to have solar panels and crop exist together without impacting crop and energy production (agrivoltaics).

- On-site energy storage: On-site energy storage systems (ESS) are required for standalone solar and wind generation since wind energy is generated more at night and solar energy during the day. For grid-connected systems, the energy storage systems can be charged slowly and can be used for fast charging the Ag-vehicles. Some of the requirements for ESS are low-cost, long-lifetime, high energy storage capacity for fast charging with a small footprint. Underground ESS would not interfere with the crop growth with flywheels as a possible solution.

- Wired and wireless fast charging: The electrified vehicles will have to be charged fast and the charging stations will have to be close to the Ag-vehicle location. As a special case, electrified drones surveying farms can also be powered through long distance wireless power transfer systems up to 20 feet or possibly longer.

- Modular electric drives: Different Ag-vehicles will have different electric drive power requirements. One opportunity in this area would be designing an electric drive module for low power applications and use multiples of these modules for high power needs. This will help manufacturing and the cost of the systems. Having common modules across vehicles will also helpwith storing a smaller number of spare parts. With multiple modules, a failure in one would still allow the vehicle continue operation even if it is at a lower power level.

\section{C.3 Next Generation Nitrogen Economy (Focus Area Leads: Brian Davison and Gabriel Veith)}

Improvements in efficient nitrogen utilization and/or fixation will decrease energy and carbon costs (currently from fossil fuels) and improve the Life Cycle Analyses (LCA) and carbon balances of all food and biomass-based processes in the mid- to long-term. The nitrogen cycle is a critical component of many 
industrial, agricultural and natural systems. $\mathrm{N}_{2}$ fixation into usable forms currently relies heavily on the energy-intensive Haber-Bosch industrial process. Industrial nitrogen consumes 3\% of the world's energy (for only 200 plants worldwide) and is a major source of emissions (Smil, 2004). Modern agriculture, which sustains the growing population, relies on application of nitrogen fertilizers. However, nitrogen-use efficiency is extremely low $(\sim 17 \%)$, representing an enormous loss in invested energy and in potential plant productivity (Erisman et al., 2008). Unused nitrogen also presents dire threats to the environment (e.g., the Gulf of Mexico hypoxic zone) and increased reactive nitrogen ( $\mathrm{Nr}$ ) emissions. Similarly, fertilizer inputs add significantly to the carbon footprint of many biofeedstocks for renewable energy. Langholtz et al. (2020) estimated that a $20 \%$ improvement in nitrogen utilization (or biological fixation) will save over $\$ 5 \mathrm{~B}$ over a decade in avoided costs in additional to the environmental benefits.

Knowledge Gaps: A) Nitrogen fixation or uptake by plants is controlled or influenced by associated microbes and is limited to just a few plant groups - we do not understand how to extend that association to other plants. We do not understand the natural nitrogen cycle and interactions and signaling within the biome - either to improve Earth system models or manipulate the plant-microbe interaction to improve uptake. B) $\mathrm{N}_{2}$ fixation is controlled by activation of key $\mathrm{N}$-metal bonds in catalysts or enzymes which are not well understood.

Research Scope and Goals: The multiple potential solutions to these issues build from current lab strengths and would benefit from a multidisciplinary approach with three thrusts:

- Alternative thermochemical and electrochemical activation and stabilization of N-H bonds.

- Improvements to biological $\mathrm{N}_{2}$ fixation and uptake efficiency where plants-microbe consortia gainonly as much nitrogen as they need; this will offset the threat of excess nitrogen and reduce the current wasted embedded energy in synthetic fertilizer.

- Improve models to understand linked nitrogen-carbon cycles to assess the fate of $\mathrm{Nr}$ and estimate consequences for air and water quality across landscape scales.

\section{C.3.1 Strategic Opportunities in Nitrogen Activation to replace the Haber-Bosch process}

The area of nitrogen activation has exploded in interest in the last 6 years primarily through extensive DFTtype simulations and classic "bubbling $\mathrm{N}_{2}$ through aqueous solutions over a metal surface" type catalysis. There are significant areas of opportunity for collaborations across ORNL, building from our core materials, characterization and theory strengths, coupled with electrochemical concepts. In addition, our unique neutron and NMR tools are ideally suited for $\mathrm{N}_{2}$ reduction due to the properties of ${ }^{14} \mathrm{~N} /{ }^{15} \mathrm{~N}$ and $\mathrm{N}-\mathrm{H}$ bonds while our simulation capabilities could be brought to bear on more complex systems than traditional modeling of $\mathrm{N}_{2}$ adsorption on metal sites. Finally, with the interest in hydrogen electrolyzers, coupling with solar power, solar fuels, carbon capture and the DOE budget request, there is an alignment of interests building from the multidisciplinary efforts at ORNL. Each of these proposed tasks occur at low temperatures and pressures and could be distributed at a local level augmenting and eventually (decades) offsetting, the need for Haber-Bosch plants ensuring food and energy security globally. This focus on low pressures and temperatures, coupled with clean hydrogen, could reduce global $\mathrm{CO}_{2}$ emissions by $3 \%$.

\section{C.3.1.1 Molten Salts and Ionic Liquids}

Sheng Dai, Bruce Pint, Richard Mayes, James Browning,Gabriel Veith, Vyacheslav (Slava) Bryanstev

Molten salt $\left(>300^{\circ} \mathrm{C}\right)$ and ionic liquid electrolysis systems have the highest reported Faradaic Efficiencies (>30\%) for the reduction of $\mathrm{N}_{2}$ to $\mathrm{NH}_{3}$ at atmospheric pressures but are not explored by the traditional 
catalysis community. ORNL has internationally recognized expertise in molten salts built from the molten salt reactor history and recent efforts in the nuclear and solar energy space focused on salt chemistry, corrosion, in situ interfaces that should be combined and investigate nitrogen reduction. Key questions include: What are the interface structures in the molten salt that mediate ammonia production? What effect does salt composition have on nitrogen reduction? Can molecular interactions be tuned to optimize $\mathrm{N}_{2}$ solubility? What active electrocatalysts are compatible with them?

\section{C.3.1.2 Reverse Fuel Cells/Electrolyzers}

\section{Todd Toops, Thomas Zawodzinski, Beth Armstrong, EdgarLara-Curzio, Alexey Serov}

Ceramic solid oxide, alkaline and polymer electrolyte fuel cell technologies can be operated in reverse to generate $\mathrm{NH}_{3}$ from water and $\mathrm{N}_{2}$. Conversion technology built from high temperatures $\left(>250^{\circ} \mathrm{C}\right)$ fuel cells have the second highest reported Faradaic efficiencies (>20\%) but are again not explored by traditional heterogeneous catalysis programs. ORNL has unique expertise in solid-oxide fuel cells and solid-acid fuel cells along with mothballed cell hardware which should be utilized. In addition, hydrogen electrolysis is a critical and growing research area that would couple well with this. Key questions include: which cathode chemistry is key to $\mathrm{N}_{2}$ activation at these temperatures and pressures? How to break the scaling relationship ( $\mathrm{N}_{2}$ adsorption and $\mathrm{NH}_{3}$ adsorption) via new cathode materials? Which solid electrolytes are optimized for proton transport and dissociation from steam? Which molten salts and ionic liquids from Section 3.3.1 are optimal for $\mathrm{NH}_{3}$ production?

\section{C.3.1.3 Nitrogen reduction under confinement}

Gabriel Veith, Zili Wu, Ashi Aditya, Robert Sacci Andrew Sutton, Timmy Ramirez-Cuesta, Jingsong Huang, Zhenglong Li, Jingsong Huang, Jacek Jakowski, Victor Fung

Several projects from LDRD's have demonstrated nitrogen reduction under confinement. These areas include electrides (Zili Wu), carbon nanospikes (Rondinone) and anion radical chemistry (Veith). The benefit of these approaches appears to be the concentration of $\mathrm{N}_{2}$ while protecting the reduced nitrogen from reactive oxygen analogous to biological fixation under anerobic conditions. Key outstanding questions: how can the confinement effect be extended to increase yield beyond the current $10 \%-15 \%$ efficiency? What materials properties are essential for this effect to work? Can theoretical models be generated to predict improved properties? What are the molecular interactions in aprotic solutions?

\section{C.3.1.4 Plasma Chemistry - John Caughman, Kai Xiao, Jingsong Huang}

The use of plasmas has been demonstrated to radically change the reaction mechanism and processes for the formation of ammonia and is not traditionally investigated. ORNL has extensive efforts in plasma chemistry through the ITER reactor and vapor phase synthesis efforts which should be applied to this area to answer key questions such as: What is the mechanism of nitrogen reduction in a plasma? Can these processes be tuned to promote the formation of $\mathrm{C}-\mathrm{N}$ bonds? How can reactors be engineered to energy efficiently convert $\mathrm{N}_{2}$ into ammonia?

\section{C.3.1.5 Combining $\mathrm{N}_{2}$ and $\mathrm{CO}_{2}$ - Robert Sacci, Zhenglong Li, Andrew Sutton, Haiying Chen, Meijun Li, Zili Wu, Jingsong Huang, Jacek Jakowski, Victor Fung}

This area is relatively unexplored but could yield significant opportunities for BOTH carbon and nitrogen fixation. This would require experimental efforts to oxidize $\mathrm{N}_{2}$ and remove electrons from $\mathrm{CO}_{2}$, which is energetically more favorable than $\mathrm{N}_{2}$ reduction. 


\section{C.3.1.6 Crosscutting initiative}

Jingsong Huang, Jacek Jakowski, Victor Fung, Vyacheslav (Slava) Bryanstev, Massimiliano Pasini Lupo, Vitalii Starchenko, Timmy Ramirez-Cuesta, James Browning, Jue Liu, Luke Damen

Underpinning these proposed tasks is extensive neutron characterization (quasielastic - proton motion, inelastic - proton containing structures of catalysts and intermediates, reflectometry - interfacial structures) and simulations of reaction environments under confined conditions. Such simulations have been performed by team members at CNMS for supercapacitors and ion double-layers.

\section{C.3.2 Improved Biological Nitrogen Fixation and Uptake Improvements}

Nitrogen fixation is carried out by certain microbes that produce nitrogenase under micro-anaerobic conditions. Efforts to improve the fundamental enzymes have had limited success. Teams should focus on the interactions of plants and microbes that either allow for nitrogen fixation or improve the efficiency of the plant to uptake and utilize available nitrogen. This will draw on biocomplexity, genomic models based on large datasets and our growing ability to manipulate associations of plants and microbes to target host effects on colonization, microbial rhizosphere capabilities and the link to the overall environment. Specific science challenges include the barriers to immunity that prevent successful colonization of noncoevolved plant hosts, the variation in colonization rate and efficiency of nitrogen fixation in natural and agronomic systems: the ecological diversity of microbial machinery involved in nitrogen fixation; understanding the energy/electron flow and reallocation in $\mathrm{N}_{2}$-fixing bacteria since nitrogen fixation is energy intensive; and issues of "missing nitrogen accounting", which may be related to microbial turnover as a source of potential available plant nitrogen at multiple time and length scales.

While the end goal is different, the underlying science and skills for this area is closely tied to the biological methods to enhance soil organic carbon (Section 1.2 above) and should be seen as a joint effort.

\section{C.3.3 Improved Models for Nitrogen (and Carbon) in Climate and Landscapes}

Scientific progress has not kept pace with human modifications to nitrogen cycles and we find ourselves unable to anticipate the magnitude and direction of future changes in the nitrogen economy. We need the capacity to estimate the magnitude of multiscale and multidimensional consequences of changes in the nitrogen economy. This needs to link current efforts on improving the modeled representation of nitrogen-cycling mechanisms (including structure to couple the nitrogen and carbon cycles in Earth-system models) to macroeconomic and technical economic assessments (elucidated by the other two thrusts) and to the ramifications perturbing the nitrogen might have for food, energy and water. We perceive an opportunity to integrate research and provide foundational data from molecular genetics to the understanding of human- modified and natural nitrogen dynamics. This should emphasize terrestrialaquatic interfaces, which have a disproportionate impact on the nitrogen cycle, specifically through removal of Nr. Specific attention is needed on understanding and predicting the fate of excess $\mathrm{Nr}$ with its ecological consequences in eutrophication of our waters and increased $\mathrm{N}_{2} \mathrm{O}$ (a greenhouse gas) release from soils.

Since the nitrogen cycle is closely linked to the carbon-cycle, this effort should be considered to be linked with the carbon assessments under Soil Health (Section 1.1 above). Models are critical tools for scaling knowledge gained from measurements and experiments over space and time. By integrating improved understanding of key processes and responses to interventions, models can be used to estimate macroscopic impacts at regional to continental scales. Models also integrate disparate processes, making them essential tools for integrating knowledge across different fields and areas of expertise. Using regional to continental scale models as an integrator, we can combine information from process-based experiments, assessments, 
remote sensing measurements and alternative management scenarios to generate integrated projections of combined effects and their interactions at societally relevant scales.

Downstream effects related to erosion and runoff of soil and fertilizer also drive environmental impacts at watershed to regional scales and an integrative understanding of how agricultural management actions drive these larger-scale impacts required integrative modeling of water, carbon and nutrient flows at regional scales.

Tackling these problems at large (regional or national) scales will require engagement of multiple ORNL capabilities including remote sensing data, road infrastructure, irrigation infrastructure, cropping practices at the field scale, plant-microbe interactions, fate of applied fertilizer, plant growth physiology, modeling of plant-soil interactions and high-performance computing.

\section{C.3.3.1 Model-data Integration and Uncertainty Quantification}

Quantifying and reducing prediction uncertainty are essential to make actionable decisions based on Earth system modeling. Land-surface models in particular contain many uncertain parameters and processes. We can identify parameters controlling key processes of interest (e.g., soil carbon accumulation) for cropland areas in an Earth system model by performing ensembles in parallel from site to global scales. Machine learning/AI techniques can be used to overcome the typically prohibitive computational expense of model sensitivity analyses and calibration to improve predictive skill. Observational constraints may include sitelevel data (e.g., eddy covariance measurements, yield data or point soil carbon and nutrient information), or gridded observations from remote sensing (e.g., solar-induced fluorescence) or upscaling (e.g., FLUXCOM). These uncertainty quantification methods may also be used to identify model biases and prioritize structural improvements (i.e., adding new processes may be necessary if model calibration fails to bring the simulation into agreement with observations).

\section{C.3.3.2 Earth System Feedbacks}

Decarbonizing the agricultural sector will have consequences for the coupled Earth System by changing local climates and affecting distant regions through teleconnections, including land-atmosphere feedbacks that may occur through changes in soil management practices, crop type or altering plant and microbial traits that impact albedo, surface roughness, nutrient and water use. These changes can affect boundary layer dynamics and convective processes resulting in changes in temperature and precipitation patterns. Changes in erosion and nutrient runoff also affect downstream conditions in rivers and alter carbon and nutrient cycling along terrestrial-aquatic interfaces and in oceanic systems. In addition to greenhouse gases, emissions of aerosols are likely to change in both quantity and spatial distribution. Over time, a decarbonization strategy must also be robust to both changes in the mean climate state and changing extremes that can cause rapid shifts in carbon fluxes (e.g., fire, floods or droughts). A coupled Earth system modeling (ESM) framework is required to quantify these impacts and minimize risk from any unintended negative consequences.

\section{C.3.3.3 Scaling}

It is highly unlikely that a fully coupled ESM will be able to include the level of detail, both in terms of spatial resolution and in process richness, needed to integrate information from all of the areas of research associated with decarbonization. A multi-scale, multi-fidelity approach allows the application of finer-scale models focused on specific science questions or spatial domains.

\section{START HEREA}




\section{ORNL Model Capabilities:}

- Land surface modeling (E3SM/ELM, Daycent): $\mathrm{C}$ and $\mathrm{N}$ cycling at field scale, scaling up to regional/continental scales. Feedbacks to climate. Uncertainty and sensitivity analysis. People: Dan Ricciuto, Peter Thornton, Ben Sulman, Xiaojuan Yang, Xiaoying Shi, John Field

- Integrated assessment modeling (GCAM): Integrating policy choices (land use, energy use) into scenarios and coupling to Earth system simulations. People: John Field?

- Detailed process-based soil organic matter modeling (MEND, CORPSE, PFLOTRAN):Chemistrybased, detailed simulations of redox, microbial processes, soil structure interactions. People: Ben Sulman, Teri O’Meara, Melanie Mayes

- Watershed-scale modeling (ATS): Simulating water, carbon and nutrient flows, erosion and contributions to eutrophication. People: Scott Painter, Ethan Coon, Saubhagya Rathore

- Bioenergy modeling group at ORNL.

\section{ORNL Modeling Gaps:}

- GCAM

- $\quad$ ELM crop modeling is mainly at ANL

In order to capture and realize these opportunities researchers from National Laboratories, Academic Institutions and the private sector would need to work in unison and would encompass the disciplines of microbiologists, plant geneticists, soil scientists, life cycle analysts and computational biologists. Potential Academic collaborating institutions would include University of Tennessee, University of Georgia, Duke University, North Carolina State University, Georgia Tech, Iowa State University, Pennsylvania State University, University of Illinois, University of Delaware, University of Notre Dame, among others. There are also several MSIs and HBCUs in the southeast U.S. that could be approached in these areas.

Funding challenges exist in several of these areas are seen as within the purview of USDA. Assessments of scenario impacts are desired without policy recommendations. Several of the areas should garner interest from EERE, from BER, from Office of Fossil Energy, and from ARPA-C.

\section{C.4 Potential Collaborators}

Initial suggestions for Potential collaborators in vehicle and propulsion systemDr. James McCarthy, Jr, Eaton Vehicle Group

Ivan Tate, CNH Industrial, Powertrain segment (Fiat Powertrain Technologies North America)

Curt Blades, Senior Vice President, Agriculture \& Forestry, Association of Equipment Manufacturers (AEM)

Dr. Girish Chowdhary (Univ of Illinois, Department of Agricultural and Biological Engineering

Dr. Scott Shearer, Ohio State Department of Food, Agricultural and Biological Engineering

Dr. Roger Hoy, Nebraska Tractor Test Laboratory 
Dr. Brij Singh, Region 4 Manager External Relationships, Intelligent Solutions Group - Emerging Technology

Danan Dou, John Deere

Dave Montgomery, Caterpillar

Julie Blumreiter, ClearFlame

Potential Partners for the Nitrogen Economy

Dr. Marta Hatzell, Georgia Tech

Dr. Shelley Minteer, University of Utah

Dr. Jason Hicks, University of Notre Dame

Dr. Jingguang Chen, Columbia University/BNL

Dr. Lauren Greenlee, Pennsylvania State University

Dr. Kathy Ayers, Nel Hydrogen (formerly Proton OnSite)

Dr. Trent Molter, SKYRE

Dr. Rich Masel, Dioxide Materials

Dr. Yushan Yan and Dr. Shimshon Gottelsfeld, University of Delaware

Dr. Santiago Rojas-Carbonell, VersogenDr. Helga Dögg Flosadóttir, Atmonia Prof. Feng Jiao, University of Delaware

\section{References and Cited Literature}

"Path to 2060: Decarbonizing the Agriculture Industry." UVA Darden School of Business. 2019. summarizes the key findings from the subject research report - Batten summary briefing: https://issuu.com/batteninstitute/docs/pathto2060-agriculture

Huber, Kristiane. 2018. Decarbonizing U.S. Agriculture, Forestry and Land Use. Center for Climate and Energy Solutions (C2ES). https://www.c2es.org/site/assets/uploads/2018/06/innovation-agriculturebackground-brief-07-18.pdf

"Agriculture and climate change - Reducing emissions through improved farming practices", McKinsey and Company, Ahmed et al. 2020.

https://www.mckinsey.com/ /media/mckinsey/industries/agriculture/our\%20insights/reducing\%20agricul ture\%20emissions \%20through\%20improved\%20farming\%20practices/agriculture-and-climatechange.pdf

Crippa, M., Solazzo, E., Guizzardi, D., Monforti-Ferrario, F., Tubiello, F. N., \& Leip, A. (2021). Food systems are responsible for a third of global anthropogenic GHG emissions. Nature Food, 2(3), 198-209. https://doi.org/10.1038/s43016-021-00225-9 
Rockström, J., Schellnhuber, H. J., Hoskins, B., Ramanathan, V., Schlosser, P., Brasseur, G. P., Gaffney, O., Nobre, C., Meinshausen, M., Rogelj, J., \& Lucht, W. (2016). The world's biggest gamble. Earth's Future, 4(10), 465-470. https://doi.org/10.1002/2016EF000392

Jansson, C., Wullschleger, S. D., Kalluri, U. C., \& Tuskan, G. A. (2010). Phytosequestration: Carbon Biosequestration by Plants and the Prospects of Genetic Engineering. BioScience, 60(9):685-696. https://doi.org/10.1525/bio.2010.60.9.6

National Academies of Sciences, Engineering and Medicine. (2019). Negative Emissions Technologies and Reliable Sequestration: A Research Agenda (p. 25259). National Academies Press. https://doi.org/10.17226/25259

Paustian, K., Larson, E., Kent, J., Marx, E., \& Swan, A. (2019). Soil C Sequestration as a Biological Negative Emission Strategy. Frontiers in Climate, 1. https://doi.org/10.3389/fclim.2019.00008

Energy Futures Initiative. "From the Ground Up: Cutting-Edge Approaches for Land-Based Carbon Dioxide Removal.” December 2020.

Sanderman, J., Hengl, T., \& Fiske, G.J. (2017). Soil carbon debt of 12,000 years of human land use. Proceedings of the National Academy of Sciences 114(36), 9575-9580.

Minasny, B., Malone, B. P., McBratney, A. B., Angers, D. A., Arrouays, D., Chambers, A., Chaplot, V., Chen, Z.-S., Cheng, K., Das, B. S., Field, D. J., Gimona, A., Hedley, C. B., Hong, S. Y., Mandal, B., Marchant, B. P., Martin, M., McConkey, B. G., Mulder, V. L., ... Winowiecki, L. (2017). Soil carbon 4 per mille. Geoderma, 292, 59-86. https://doi.org/10.1016/j.geoderma.2017.01.002

Lavallee, J. M., Soong, J. L., \& Cotrufo, M. F. (2020). Conceptualizing soil organic matter into particulate and mineral-associated forms to address global change in the 21st century. Global Change Biology, 26(1), 261-273. https://doi.org/10.1111/gcb.14859

Paustian, K., Campbell, N., Dorich, C., Marx, E., \& Swan, A. (2016). Assessment of potential greenhouse gas mitigation from changes to crop root mass and architecture (No. 1339423; p. 1339423).

https://doi.org/10.2172/1339423

Yang Song, Daniel Johnson, Rui Peng, Dale K. Hensley, Peter V. Bonnesen, Liangbo Liang, Jingsong Huang, Fengchang Yang, Fei Zhang, Rui Qiao, Arthur P. Baddorf, Timothy J. Tschaplinski, Nancy L. Engle, Marta C. Hatzell, Zili Wu, David A. Cullen, Harry M. Meyer III, Bobby G. Sumpter, Adam J. Rondinone, (2018). A physical catalyst for the electrolysis of nitrogen to ammonia. Science Advances, 4: pg. e1700336

"Nature of Reactive Hydrogen for Ammonia Synthesis over a Ru/C12A7 Electride Catalyst" James Kammert, Jisue Moon, Yongqiang Cheng, Luke Daemen, Stephan Irle, Victor Fung, Jue Liu, Katharine Page, Xiaohan Ma, Vincent Phaneuf, Jianhua Tong, Anibal J. Ramirez-Cuesta, Zili Wu, (2020) J. Am. Chem. Soc. 142:7655-7667.

Patrick M. Barboun, Luke L. Daemen, Craig Waitt, Zili Wu, William F. Schneider and Jason C. Hicks. (2021). Inelastic Neutron Scattering Observation of Plasma-Promoted Nitrogen Reduction Intermediates on $\mathrm{Ni} / \gamma-\mathrm{Al}_{2} \mathrm{O}_{3}$. ACS Energy Lett. 6, pg. 2048-2053.

Jisue Moon, Yongqiang Cheng, Luke Daemen, Eric Novak, Anibal J. Ramirez-Cuesta, Zili Wu. (2021). On the Structural Transformation of Ni/ $\mathrm{BaH}_{2}$ During a $\mathrm{N}_{2}-\mathrm{H}_{2}$ Chemical Looping Process for Ammonia 
Synthesis: A Joint In Situ Inelastic Neutron Scattering and First-Principles Simulation Study. Topics in Catalysis (in press).

Smil, V. (2004) Enriching the Earth: Fritz Haber, Carl Bosch and the Transformation of World Food Production (MIT Press, Cambridge, MA, 2004).

Erisman, Jan Willem; Sutton, Mark A.; Galloway, James; et al (2008). How a century of ammonia synthesis changed the world, NATURE GEOSCIENCE 1(10): 636-639. 


\section{APPENDIX D. ABBREVIATED TERMS}

AI

ANL

ARPA-C

ARPA-E

ASABE

ASTM

BER

BETO

C

CEO

CORPSE

CSU

DOE

EERE

FAIR

FECM

GHG

GWAS

ISO

LBNL

LTAR

LTER

MAOM

ML

MODEX

MSU

$\mathrm{N}$

NGO

NRI

NSF

ORNL

PNNL

POM

QTL

SILC

SIP

UIUC

USDA artificial intelligence

Argonne National Laboratory

Advanced Research Projects Agency - Climate

Advanced Research Projects Agency-Energy

American Society of Agricultural and Biological Engineers

ASTM International

DOE Office of Biological and Environmental Research

DOE Bioenergy Technologies Office

carbon

corporate executive officer

Carbon, Organisms, Rhizosphere, and Protection in the Soil Environment(model)

Colorado State University

US Department of Energy

DOE Office of Energy Efficiency and Renewable Energy

Findable, Accessible, Interoperable, and Reusable

DOE Office of Fossil Energy and Carbon Management

greenhouse gas

genome-wide association study

International Organization of Standardization

Lawrence Berkeley National Laboratory

USDA Long-Term Agroecosystem Research (Network)

NSF Long-Term Ecological Research (Network)

mineral-associated organic matter

machine learning

Model Observation/Experiment (process)

Michigan State University

nitrogen

nongovernmental organization

Noble Research Institute

National Science Foundation

Oak Ridge National Laboratory

Pacific Northwest National Laboratory

particulate organic matter

quantitative trait locus

Sustainability Innovation Lab at Colorado

stable isotope probing

the University of Illinois at Urbana-Champaign

US Department of Agriculture 




(n)

